\title{
Late Fuel Post-Injection Influence on the Dynamics and Efficiency of Wall-Flow Particulate Filters Regeneration
}

\author{
José Ramón Serrano ${ }^{(D)}$, Pedro Piqueras *(D), Joaquín de la Morena and Enrique José Sanchis \\ CMT-Motores Térmicos, Universitat Politècnica de València, Camino de Vera s/n, 46022 Valencia, Spain \\ * Correspondence: pedpicab@mot.upv.es; Tel.: +34-963-877-650
}

Received: 7 November 2019; Accepted: 4 December 2019; Published: 9 December 2019

\begin{abstract}
Late fuel post-injections are the most usual strategy to reach high exhaust temperature for the active regeneration of diesel particulate filters. However, it is important to optimise these strategies in order to mitigate their negative effect on the engine fuel consumption. This work aims at understanding the influence of the post-injection parameters, such as its start of injection and its fuel quantity, on the duration of the regeneration event and the fuel consumption along it. For this purpose, a set of computational models are employed to figure out in a holistic way the involved phenomena in the interaction between the engine and the exhaust gas aftertreatment system. Firstly, an engine model is implemented to evaluate the effect of the late fuel post-injection pattern on the gas properties at the exhaust aftertreatment system inlet in different steady-state operating conditions. These are selected to provide representative boundary conditions of the exhaust gas flow concerning dwell time, exhaust temperature and $\mathrm{O}_{2}$ concentration. In this way, the results are later applied to the analysis of the diesel oxidation catalyst and wall-flow particulate filter responses. The dependence of the diesel particulate filter (DPF) inlet temperature is discussed based on the efficiency of each post-injection strategy to increase the exhaust gas temperature. Next, the influence on the dynamics of the regeneration of the post-injection parameters through the change in gas temperature and $\mathrm{O}_{2}$ concentration is finally studied distinguishing the pre-heating, maximum reactivity and late soot oxidation stages as well as the required fuel consumption to complete the regeneration process.
\end{abstract}

Keywords: internal combustion engines; emissions; particulate matter; wall-flow particulate filter; oxidation catalyst; post-injection; regeneration; fuel consumption

\section{Introduction}

The regulation of pollutant emissions in internal combustion engines has continuously become more stringent in recent years. This fact drove the engine development process, aimed at reducing the fuel consumption and the environmental impact. One of the results of this trend is the use of exhaust gas aftertreatment systems (ATS) [1]. In the case of the particulate matter, wall-flow particulate filters $(\mathrm{PF})$ are nowadays a standard technology necessary to fulfil current regulations because of their high filtration efficiency, both for diesel (diesel particulate filter-DPF) [2] and gasoline (GPF) [3] engines. In this regard, PFs allow an effective reduction of the particle emission both in terms of mass and particle number, with filtration efficiency typically over $90 \%$ dependent on several parameters such as the DPF gas flow [4], the particle size, the soot mass load or the fuel [5].

The use of the particulate filter has a great impact on the engine performance and its fluid-dynamic behaviour, increasing the exhaust backpressure [6] and affecting the wave dynamics of the exhaust line [7]. The accumulation of soot inside and on the porous walls of the filter [8] aggravates these effects and leads the engine specific fuel consumption to increase [9]. For this reason, and taking into 
account the limited capacity of the filter for soot accumulation [10], after a certain operating time it is necessary to induce a regeneration process consisting of the oxidation of the soot particulates stored inside the filter [11]. Two different strategies are used for this purpose. Active regenerations, which are promoted periodically, make use of an external energy source [12] to trigger the soot oxidation process. Instead, passive regeneration strategies produce such oxidation without an external energy source. These passive solutions help to reduce the frequency of active events in diesel engines [13] and are even sufficient in gasoline engines [14].

In the particular case of active regenerations, different techniques can be used to increase the exhaust gas temperature until the level needed for the soot to oxidise [15]. Among them, the most common one is the use of fuel post-injections, which consists of the injection of an amount of fuel in a single or separate portions after the main injection [16] during the late expansion stroke [17]. The extra fuel injection gives as a result a significant increase of the concentration of unburned hydrocarbons (HC) in the exhaust gases. Once these hydrocarbons arrive to the diesel oxidation catalyst (DOC), their oxidation produces a significant increase in the temperature at the DPF inlet [18]. However, these strategies imply an increase of the fuel consumption as a function of the impact on the specific fuel consumption and on the regeneration duration. Thus, it is necessary to optimise them to reduce as much as possible this penalty [19].

The main parameters to define the post-injection pattern in terms of the impact on the fuel consumption are the delay of the injection command with respect to the main injection timing [20] and the fuel mass rate during this event [16]. Both parameters play a significant role in the properties of the exhaust gas arriving to the catalyst, mainly in terms of its temperature and the HC concentration [21]. In order to maximise the regeneration efficiency it is typical to combine the post-injection strategies with other engine control actuations, such as to act on the exhaust gas recirculation (EGR) valve, aimed at increasing the exhaust temperature [22] or the closure of the intake throttle valve, limiting the air flow coming into the cylinders in order to achieve richer equivalence ratio mixtures and higher HC concentration during the main combustion event [23]. Parks et al. [24] studied the relationship between the exhaust gas temperature and the optimal post-injection timing for the regeneration. They concluded that for low temperature it was necessary to cause an increase of the temperature inside the cylinder during the combustion so that the post-injection had to be performed relatively close to the main injection event to ensure its ignition. Instead, when the exhaust temperature was higher it was more efficient to induce the oxidation in the catalyst so that the post-injection event should be delayed.

Another important aspect to define the regeneration strategy is related to the properties of the fuel, which determine the specific composition of the HC [25] and, consequently, the DOC response [26]. Chen et al. [27] concluded that the regeneration was slower when using biodiesel fuel due to the lower temperature reached in the DOC compared to a regular diesel fuel. In this sense, the research done by Jeftić et al. [25] analysed the HC, CO and soot emissions produced by the post-injection of n-butanol and diesel fuel, highlighting the change in the composition of HC due to the different fuels and the lower soot emissions characteristic of the operation with n-butanol.

Defining the optimum regeneration strategy as the one leading to the minimum fuel consumption, i.e., the optimum combined impact of post-injection rate and regeneration duration, the current work analyses the efficiency of the timing and fuel mass rate of late fuel post-injection events in terms of exhaust gas temperature increase, change in specific fuel consumption and dynamics of the active regeneration. Other important aspects for the definition of the regeneration strategy, such as the fuel dilution inside the engine oil [28] or the thermal fatigue in the particulate filter [29], are out of the scope of this work.

In order to perform this study, a set of computational models are used to analyse in detail the linked engine and ATS response. An engine model implemented in GT-POWER [30] is used to predict the influence of the post-injection event on the specific fuel consumption and the gas properties at the DOC inlet. These boundary conditions are next applied as input for dedicated lumped DOC and DPF 
models, which were previously validated within a wide range of engine experimental data. Firstly, the dependence of the DPF inlet temperature on the post-injection settings is analysed, defining the efficiency of each strategy from the exhaust gas temperature increase. The influence on the dynamics of the regeneration of the temperature increase and the available $\mathrm{O}_{2}$ concentration at the DPF inlet is finally studied. This is done to make the focus centre on the changes in the pre-heating, maximum reactivity and late soot oxidation stages as a function of the post-injection parameters. This way, the impact on the duration and the required fuel consumption of each stage is evaluated, making evident the variation in sensitivity to the post-injection timing and fuel mass rate of different engine operating conditions.

\section{Modelling Tools}

Figure 1 shows schematically the engine used in this work as an exhaust gas generator. This way, different representative boundary conditions of the exhaust gas flow useful for the analysis of DPF active regeneration strategies are defined concerning dwell time, exhaust temperature and $\mathrm{O}_{2}$ concentration. The main characteristics of the engine and the ATS, which was composed by a close-coupled DOC and DPF brick, are summarised in Tables 1 and 2 respectively. In particular, a 1D gas dynamics model was built in GT-POWER software. To do that the engine was tested coupled to an asynchronous dynamometer for engine speed and torque control. The main characteristics of the instrumentation used to measure the air and fuel mass flow as well as the flow properties in the intake and exhaust lines are summarised in Table 3. The gas composition at the DOC inlet and outlet was measured by a Horiba Mexa 7100 gas analyser and AVL 439 opacimeter. A detailed calibration of the engine model is provided in [31].

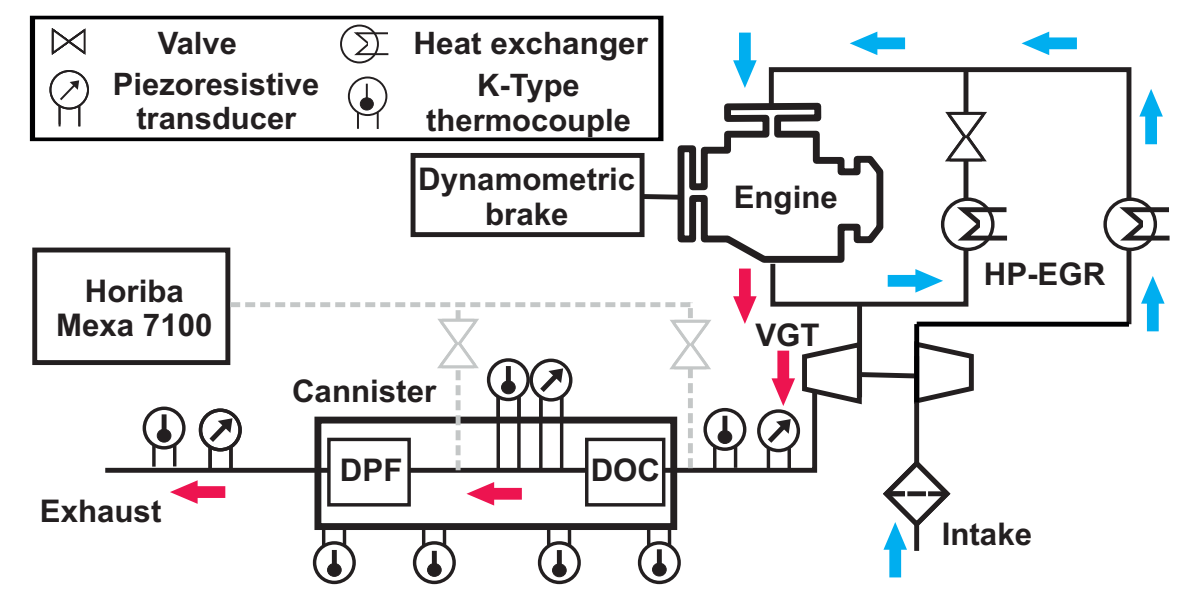

Figure 1. Scheme of the experimental setup used for the model calibration tests.

Table 1. Main engine parameters.

\begin{tabular}{lc}
\hline Engine type & HSDI diesel \\
Emission standards & Euro 4 \\
Displacement & $1997 \mathrm{~cm}^{3}$ \\
Bore & $85.0 \mathrm{~mm}$ \\
Stroke & $88 \mathrm{~mm}$ \\
Number of cylinders & 4 in-line \\
Compression ratio & $15.5: 1$ \\
Rated power @ speed & $120 \mathrm{~kW} @ 3750 \mathrm{rpm}$ \\
Rated torque @ speed & 340 Nm @ 2000 rpm \\
Fuel injection & Common-rail direct fuel injection \\
Turbocharger & VGT \\
EGR & Cooled high pressure \\
\hline
\end{tabular}


Table 2. Geometrical parameters of the diesel oxidation catalyst (DOC) and the diesel particulate filter (DPF).

\begin{tabular}{lcc}
\hline & DOC & DPF \\
\hline Diameter [mm] & 172 & 172 \\
Monolith length [mm] & 82 & 100 \\
Channel cross-section & Square & Square \\
Cell density [cpsi] & 400 & 200 \\
Cell size [mm] & 1.17 & 1.39 \\
Wall thickness [mm] & 0.101 & 0.4 \\
Catalytic area [m $\left.{ }^{2}\right]$ & 5.5 & \\
Filtration area $\left[\mathrm{m}^{2}\right]$ & & 2.11 \\
Porosity [-] & & 0.4 \\
Mean pore diameter $[\mu \mathrm{m}]$ & & 21.4 \\
Permeability $\left[\times 10^{-13} \mathrm{~m}^{2}\right]$ & & 7.69 \\
\hline
\end{tabular}

Table 3. Characteristics of the instrumentation.

\begin{tabular}{cccc}
\hline Magnitude & Sensor & Range & Error \\
\hline Temperature & Thermocouple type K & {$\left[-200-1200{ }^{\circ} \mathrm{C}\right]$} & $\pm 1.1^{\circ} \mathrm{C}$ or $0.4 \%$ (actual value) \\
Pressure & Piezoresistive PMA P40 & {$[0-6 \mathrm{bar}]$} & $\pm 0.3 \%$ (full scale) \\
Fuel mass flow & Gravimetric balance AVL733S & {$[0-27 \mathrm{~kg} / \mathrm{h}]$} & $\pm 0.12 \%$ (full scale) \\
Air mass flow & Sensyflow ABB & {$[0-720 \mathrm{~kg} / \mathrm{h}]$} & $\pm 1 \%$ (actual value) \\
\hline
\end{tabular}

The predictive capabilities of the engine model were improved by specific sub-models. This way, the DI-Pulse (direct-injection diesel multi-pulse mode) model available in GT-POWER was used to simulate combustion process and the raw pollutant emissions from the injection rate profile [30]. The fuel mass is tracked as it is injected, evaporates, mixes with surrounding gas and finally burns. To do that, each injection event is treated as an injection pulse that is tracked separately from all the pulses, without a distinction between pilot, main or post-injection being that the injected fuel is added to the spray unburned zone. Therefore, the timing and the fuel mass rate define the late fuel post-injection to predict the effect that the modification of the injection profile has on the combustion and the pollutants formation. Concerning the last, the $\mathrm{CO}$ concentration was calculated based on the thermodynamic equilibrium whilst the raw $\mathrm{HC}$ concentration was determined as the difference between the injected and burned fuel mass. The amount of soot was calculated applying the Hiroyasu model [30].

On the other hand, the turbocharger and ATS sub-models available in GT-POWER were replaced by dedicated user-functions available in OpenWAM [32], which is an open-source gas dynamics software developed by CMT-Motores Térmicos [33]. The turbocharger sub-model was applied aimed at a more precise simulation of the heat transfer [34] and the mechanical losses [35] in the turbocharger thus contributing to improving the prediction of the temperature at the turbine outlet [31].

Once flow properties were defined at the ATS inlet, specific DOC and DPF models were applied to assess the impact of the active regeneration strategy on the soot oxidation. For the sake of completeness, these models are next briefly described.

\subsection{DOC Model}

A lumped modular DOC model is applied to compute the main physical and chemical processes affecting the flow properties at the DPF inlet [26]. The model is based on the solution of the pressure drop, heat transfer and the chemical reactivity processes [36]. Since this work is focused on the analysis of the DPF response during the regeneration, the heat transfer and chemical processes are modelled directly imposing the turbine outlet flow properties, i.e., mass flow, composition, pressure and temperature, as boundary conditions. 
The pressure drop across the DOC is modelled based on a phenomenological approach assuming incompressible flow as [36]

$$
\Delta p_{D O C}=\frac{1}{2} \varsigma_{D O C} \rho_{i n} u_{i n}^{2}
$$

where $\rho_{\text {in }}$ is the DOC inlet density, $u_{\text {in }}$ is the DOC inlet velocity and $\varsigma_{D O C}$ is the pressure drop coefficient of the device. This coefficient is specific to the system geometry and obtained experimentally as a function of the Reynolds number. The heat transfer phenomena are simulated applying a lumped nodal scheme adapted from a 1D modelling approach [37]. The model accounts for the gas to wall heat exchange and the heat losses towards the environment. In addition, since the active regeneration is a transient process, the thermal inertia of the monolith substrate and the external canning is also considered to provide the temperature evolution at the DPF inlet. The nodal schemes corresponding to the monolith and the DOC canning are represented in Figure 2 [26].

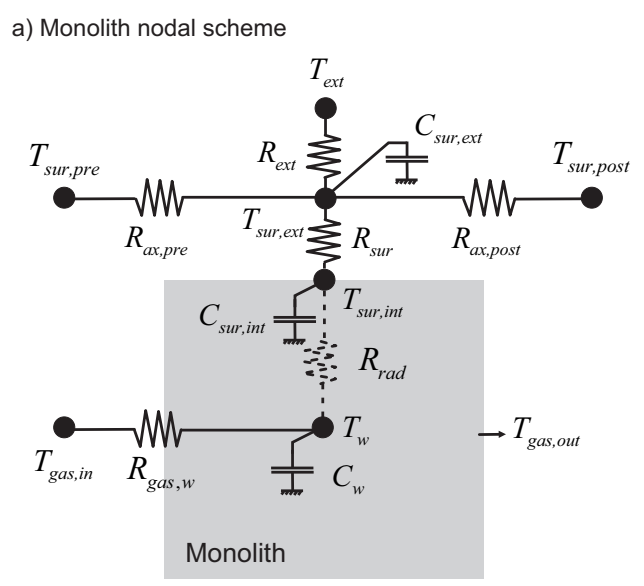

b) Canning equivalent thermal resistance

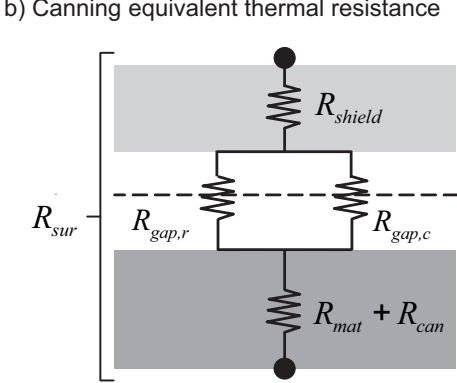

Figure 2. Monolith and canning nodal schemes for heat transfer process solution.

The model definition is based on the discretization of the general heat transfer equation by centred explicit finite differences. If axial and radial heat transfer is assumed, the wall temperature at time-step $p+1$ and node $(i, j)$ is determined considering the gas temperature and the substrate-canning state at the previous time-step $p$. Taking into account the definition of every control volume, i.e., thermal properties and heat transfer area, the substrate and canning temperatures are finally computed as:

$$
\begin{aligned}
& T_{w}^{p+1}=\frac{\Delta t}{C_{w}^{p}}\left(\sum_{k} \frac{T_{k}-T_{w}^{p}}{R_{k}}+\dot{q}_{r}^{p}\right)+T_{w}^{p} \\
& T_{\text {sur }, \text { int }}^{p+1}=\frac{\Delta t}{C_{\text {sur, int }}^{p}}\left(\frac{T_{w}^{p}-T_{\text {sur, int }}^{p}}{R_{\text {rad }}^{p}}+\frac{T_{\text {sur }, \text { ext }}^{p}-T_{\text {sur }, \text { int }}^{p}}{R_{\text {sur }}^{p}}\right)+T_{\text {sur, int }}^{p} \\
& T_{\text {sur }, \text { ext }}^{p+1}=\frac{\Delta t}{C_{\text {sur }, \text { ext }}^{p}}\left(\frac{T_{\text {ext }}-T_{\text {sur }, \text { ext }}^{p}}{R_{\text {ext }}^{p}}+\frac{T_{\text {sur }, \text { int }}^{p}-T_{\text {sur }, \text { ext }}^{p}}{R_{\text {sur }}^{p}}+\right. \\
& \left.\frac{T_{\text {sur }, \text { pre }}^{p}-T_{\text {sur, }, x t}^{p}}{R_{a x, \text { pre }}^{p}}+\frac{T_{\text {sur }, \text { post }}^{p}-T_{\text {sur }, \text { ext }}^{p}}{R_{\text {ax,post }}^{p}}\right)+T_{\text {sur,ext }}^{p} .
\end{aligned}
$$

According to Equations (2)-(4), the substrate temperature $\left(T_{w}\right)$, the internal surface temperature $\left(T_{\text {sur, int }}\right)$ and the external surface temperature $\left(T_{\text {sur,ext }}\right)$ are governed by the thermal capacity $(C)$ and 
the equivalent thermal resistance between two neighbouring nodes $(R)$, whether gas, substrate or canning. The term $\dot{q}_{r}$ is related to the heat power of the chemical reactions taking place in the washcoat.

The DOC chemical mechanism considers the $\mathrm{CO}$ and $\mathrm{HC}$ oxidation as well as the physisorption of $\mathrm{HC}$ on the zeolites present in the washcoat and the NOx redox reactions:

$$
\begin{gathered}
\mathrm{CO}+\frac{1}{2} \mathrm{O}_{2} \rightarrow \mathrm{CO}_{2} \\
\mathrm{C}_{n} \mathrm{H}_{m}+\left(n+\frac{m}{4}\right) \mathrm{O}_{2} \rightarrow n \mathrm{CO}_{2}+\frac{m}{2} \mathrm{H}_{2} \mathrm{O} \\
\mathrm{C}_{n} \mathrm{H}_{m}+\mathrm{Zeol} . \rightleftarrows \mathrm{C}_{n} \mathrm{H}_{m} \bullet \mathrm{Zeol} . \\
\mathrm{NO}+\frac{1}{2} \mathrm{O}_{2} \rightleftarrows \mathrm{NO}_{2} .
\end{gathered}
$$

The conversion efficiencies of $\mathrm{HC}$ and $\mathrm{CO}$ are calculated by the integration in the axial direction of the 1D transport equations of these species in the gas bulk and over the catalytic surface. Assuming quasi-steady flow, these are written as

$$
\begin{gathered}
u_{i n} \frac{d X_{n}}{d x}=-S_{p, g a s} k_{m, n}\left(X_{n}-X_{n, w c}\right) \\
\sum_{j} \alpha_{n} R_{j, n}+S_{p, w c} k_{m, n}\left(X_{n}-X_{n, w c}\right)=0,
\end{gathered}
$$

where Equation (9) is the bulk gas chemical species conservation equation and Equation (10) represents the chemical species transport in the washcoat of the pollutant species $n$. The bulk gas transport equation takes into account the convective transport of the species along the monolith channels and the bulk mass transfer towards the washcoat interface. As described by Equation (10), the gaseous species are then transported by diffusion from the interface to the washcoat internal volume, where the reaction takes place in the active sites.

The reaction rate $\left(R_{n}\right)$ for every pollutant species $n$ accounts for all reactions $j$ in which it is involved. It is calculated from the Arrhenius kinetic constant assuming first-order kinetics and including limitations due to inhibition and internal pore diffusion [26]. Due to the minor effect of $\mathrm{NO}_{2}$ in the soot oxidation during active regeneration processes and the high temperature in the DOC during this process [38], the $\mathrm{NO}_{2}$ / NOx ratio at the DOC outlet was determined assuming thermodynamic equilibrium [39]. Therefore, the reaction rate for the $\mathrm{CO}$ and $\mathrm{HC}$ oxidation reactions is written as

$$
R_{o x, n}=\eta_{i n t, o x, n} \frac{k_{o x, n}}{G_{o x, n}} X_{O_{2}} X_{n, w c,}
$$

whilst the HC adsorption and desorption reaction rates are given by:

$$
\begin{gathered}
R_{a d s, H C}=\eta_{i n t, a d s, H C} k_{a d s, H C}\left(1-\theta_{H C}\right) \psi_{H C} X_{H C, w c} \\
R_{d e s, H C}=\eta_{i n t, d e s, H C} k_{d e s, H C} \theta_{H C} \psi_{H C} .
\end{gathered}
$$

\subsection{DPF Model}

The gas properties at the DOC outlet define the boundary conditions for the modelling of the DPF. Like in the DOC case, a modular lumped model is employed in the DPF, including sub-models for pressure drop and heat transfer besides specific routines to account for filtration, regeneration and porous medium properties. 
The amount of soot cumulated in the DPF determines the dynamics of the filtration [40] and regeneration [38], as well as the pressure drop [41]. The variation in the soot mass inside the DPF is modelled as a function of the filtrated and oxidised soot amounts per unit of time according to Equation (14),

$$
\Delta m_{s}=\left(\dot{m}_{s, f i l t}-\dot{m}_{s, r e g}\right) \Delta t
$$

where $\Delta m_{s}$ is the variation of DPF soot mass per time-step, $\dot{m}_{s, f i l t}$ is the filtrated soot mass rate, $\dot{m}_{s, r e g}$ is the oxidised soot mass rate and $\Delta t$ is the time-step duration.

The amount of soot oxidised per unit of time as well as the heat released during the regeneration are determined from the depletion rate of the gaseous reactants depletion rate $\left(\mathrm{O}_{2}\right.$ and $\left.\mathrm{NO}_{2}\right)$, as shown in Equation (15),

$$
\dot{m}_{s, \text { reg }}=M_{\mathrm{C}}\left(-\frac{1}{\alpha_{\mathrm{NO}_{2}}} \frac{\partial n_{\mathrm{NO}_{2}}}{\partial t}-\frac{1}{\alpha_{\mathrm{O}_{2}}} \frac{\partial n_{\mathrm{O}_{2}}}{\partial t}\right)
$$

where $M_{C}$ is the Carbon molecular weight, $\alpha$ is the stoichiometric coefficient of the gaseous reactant and $\frac{\partial n}{\partial t}$ is the depletion rate of each reactant expressed in mole terms. The depletion rate is obtained solving the reactants species transport along the porous medium, i.e., particulate layer and loaded porous wall region, according to Equation (16)

$$
u_{w} \frac{\partial X_{n}}{\partial z}=-\left(S_{p, e x t}+\eta_{i n t_{n}} S_{p, i n t}\right) \alpha_{n} k_{n} \frac{K_{S_{n}} p_{n}}{1+K_{S_{n}} p_{n}},
$$

which considers the diffusion of the reactants into the soot particles and their adsorption according to a Langmuir isotherm, as discussed in [38]. In particular, the terms $S_{p, e x t}$ and $S_{p, i n t}$ represent the specific external and internal surfaces of the soot particle, respectively, being $\eta_{i n t_{n}}$ the internal pore diffusion efficiency. Additionally, $K_{S_{n}}$ and $p_{n}$ are the adsorption constant and the partial pressure of reactant $n$.

\subsection{ATS Models Calibration}

Table 4 summarises the chemical parameters in the DOC model, both for Arrhenius kinetic terms (Equation (17)) and inhibition terms (Equation (18)) [42].

$$
\begin{gathered}
k_{r}=P_{f, r} e^{-\frac{E_{a_{r}}}{R T_{w}}} \\
G_{o x}=T_{w}\left(1+K_{1} X_{C O, w c}+K_{2} X_{H C, w c}\right)^{2}\left(1+K_{3} X_{C O, w c}^{2} X_{H C, w c}^{2}\right)\left(1+K_{4} X_{N O, w c}^{0.7}\right)
\end{gathered}
$$

Table 4. Kinetic parameters of the DOC model.

\begin{tabular}{cccccccc}
\hline \multicolumn{3}{c}{ Kinetic Constants } & & & \multicolumn{2}{c}{ Inhibition Term } \\
& $\mathbf{P}_{\mathbf{f}}\left[\mathbf{s}^{-1}\right]$ & $\mathbf{E}_{\mathbf{a}}[\mathbf{J} / \mathbf{m o l}]$ & & & $\mathbf{P}_{\mathbf{f}}[-]$ & $\mathbf{E}_{\mathbf{a}}[\mathbf{J} / \mathbf{m o l}]$ \\
\cline { 1 - 2 } \cline { 5 - 7 } HC adsorption & 2.7 & 0 & & $\mathrm{~K}_{1}$ & 555 & -7990 \\
HC desorption & 100 & 65,000 & & $\mathrm{~K}_{2}$ & $1.58 \times 10^{3}$ & -3000 \\
HC oxidation & $1.7 \times 10^{17}$ & 90,000 & & $\mathrm{~K}_{3}$ & 2.98 & $-96,534$ \\
CO oxidation & $3.3 \times 10^{17}$ & 85,000 & & $\mathrm{~K}_{4}$ & $4.79 \times 10^{5}$ & 31,036 \\
\hline
\end{tabular}

This set of parameters was obtained from specific tests in steady-state and transient conditions. Figure 3 shows the comparison between experimental and modelling results for DOC outlet gas temperature and pollutants conversion efficiencies. The tests covered three engine speeds (1500 rpm, $2000 \mathrm{rpm}$ and $2500 \mathrm{rpm}$ ) and an engine load variation from 5\% to $40 \%$. The combination of these engine speeds and loads contributed to vary the mass flow and the gas temperature at the DOC so that the low to high conversion efficiency range was tested accounting for chemical kinetics, i.e., 
temperature controlled and dwell time, i.e., mass flow controlled, effects. The tests were performed in different series corresponding to each engine speed with increasing load. Each operating condition was maintained for $300 \mathrm{~s}$ to ensure thermal stabilisation before the measurement and transitioning to the following load step.

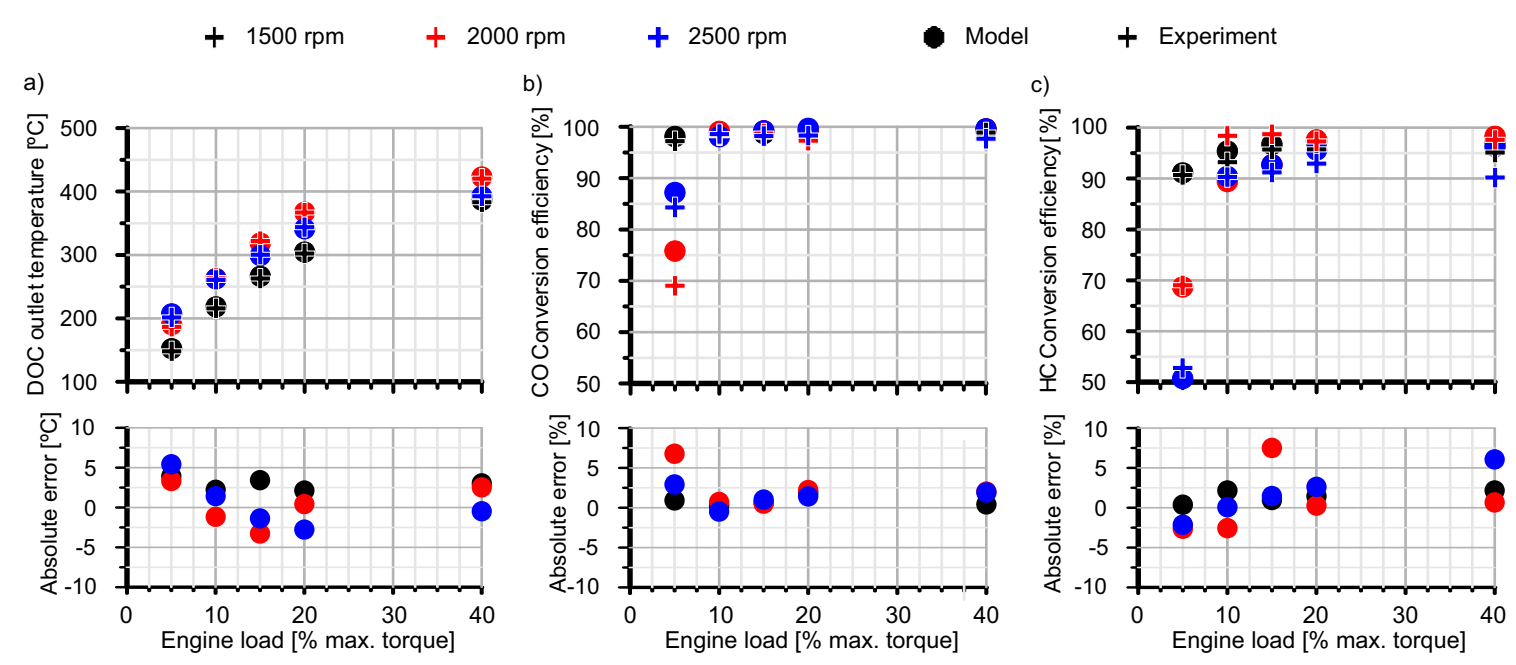

Figure 3. Comparison between experimental and modelled results under steady-state conditions of (a) DOC outlet gas temperature, (b) CO conversion efficiency and (c) hydrocarbons (HC) conversion efficiency.

Thus, Figure 3a shows the modelled DOC outlet gas temperature compared to the experimental data. The high accuracy to predict this temperature, with an absolute error ranging $\pm 5^{\circ} \mathrm{C}$, is critical since it is one of the most important parameters to evaluate the effects of the fuel late post-injection on the DPF regeneration. In turn, this good agreement results from an accurate prediction of the pollutants conversion efficiency, which is shown in plots (b) and (c) of Figure 3 for $\mathrm{CO}$ and HC respectively together with the absolute error. It is possible to observe that the $\mathrm{CO}$ conversion efficiency is below $90 \%$ for the points with a lower inlet temperature due to chemical kinetic limitations. The only exception to this behaviour corresponds to the point at $1500 \mathrm{rpm}$ and $5 \%$ in engine load, where the conversion efficiency is higher thanks to the longer residence time. For the rest of the operating points, characterised by higher exhaust temperature (over $200^{\circ} \mathrm{C}$ ), the conversion efficiency is higher than $95 \%$. Similarly, the operating points with the lowest inlet temperature have HC conversion efficiency below $90 \%$. In these points, the obtained conversion efficiency is due to two different phenomena. On the one hand, the temperature is not enough to ensure a complete oxidation of the $\mathrm{HC}$ in the exhaust gas. On the other hand, this low temperature promotes the HC adsorption on the zeolite washcoat. Moreover, it has to be considered that the zeolite is partially saturated due to the $\mathrm{HC}$ cumulated during the thermal stabilisation. Again, once the temperature reaches $200{ }^{\circ} \mathrm{C}$ the conversion efficiency increases over $90 \%$. The variations of the efficiency observed in this area are due to differences in temperature and pollutants concentration, affecting the catalyst inhibition processes. However, the model well captures the experimental trends observed.

The performance of the DOC model was also evaluated against highly transient operation during a complete Worldwide harmonized Light duty Test Cycle (WLTC). Again, the comparison between experimental and modelled DOC outlet gas temperature and pollutants conversion efficiency in Figure 4 confirms the good ability of the model to reproduce the DOC response. The trend in outlet gas temperature is very well captured so that the thermal inertia of the DOC monolith is properly represented. Only a shift between the experimental and modelled temperature is observed along the cycle. It is supposed to be related to the thermal inertia of the thermocouples, as discussed by Guardiola et al. [43]. In particular, the DOC inlet temperature is very dynamic. It indicates that this 
measurement might be affected (delayed) by the thermocouple thermal inertia. As a consequence, the modelled outlet gas temperature is also delayed with respect to the actual one. In the outlet section, although the measured DOC outlet temperature is also influenced by the dynamics of the thermocouple response, the measurement is closer to the actual temperature. This is because of the fact that the thermal inertia of the DOC governs the temperature profile, which tends to be quasi-steady.

Figure 4 shows the evolution of the cumulated conversion efficiency of $\mathrm{CO}$ and $\mathrm{HC}$ in plots (b) and (c) respectively. Since the cumulated conversion efficiency is considered, a small deviation in the instantaneous prediction would have a great influence at the early stages. This is observed in the CO cumulated conversion efficiency. The model predicts $0 \%$ in CO cumulated conversion efficiency until second 40. At this time, it starts to increase, i.e., the substrate temperature is high enough to promote the $\mathrm{CO}$ oxidation and the instantaneous conversion efficiency is progressively increasing. When the model predicts the initiation of $\mathrm{CO}$ oxidation, the experimental results also present a minimum and both signals tend to converge. However, the experimental $\mathrm{CO}$ cumulated conversion efficiency is sharply decreasing during the early WLTC. Being that the temperature is very low, it is attributed to an initial instantaneous measurement error that is progressively corrected by the cumulated result. Therefore, despite these minor differences in $\mathrm{CO}$, a good correlation between the model and the experiment can be assumed from the start of the cycle. The model performance evidences the precise modelling of the substrate temperature and the chemical kinetics over the WTLC concerning both oxidation and also adsorption-desorption in the particular case of HC.

a)

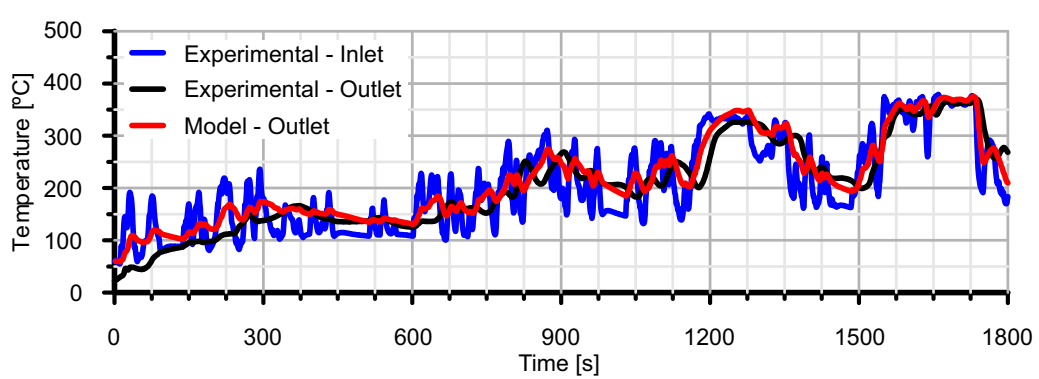

b)

c)
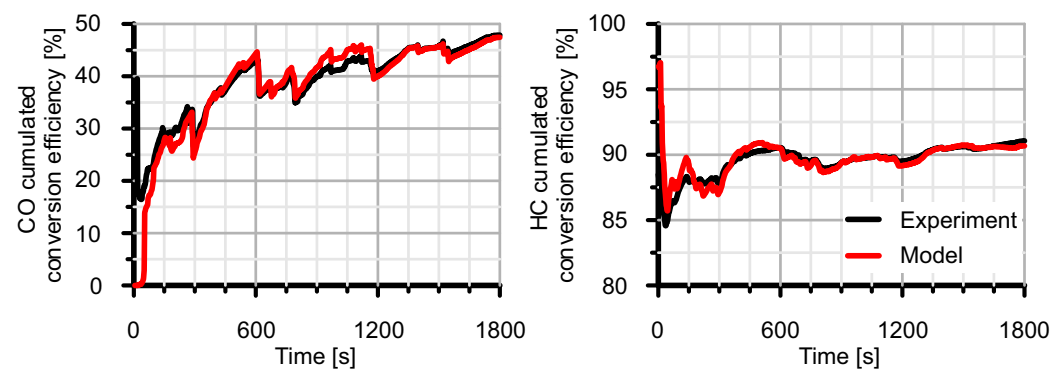

Figure 4. Comparison between experimental and modelled results under Worldwide harmonized Light duty Test Cycle (WLTC) conditions of (a) DOC outlet gas temperature, (b) CO conversion efficiency and (c) HC conversion efficiency.

Concerning the DPF model, active and passive regeneration tests were performed to calibrate the soot oxidation kinetic constants, which are defined in Table 5. The active regeneration event is represented in Figure 5. The engine was run at $1500 \mathrm{rpm}$ and $50 \mathrm{Nm}$ until the soot loading reached $5.5 \mathrm{~g} / \mathrm{L}$. Next, the active regeneration was triggered on a steady-state condition of $2000 \mathrm{rpm}$ and $90 \mathrm{Nm}$ applying a $6 \mathrm{mg} / \mathrm{cc}$ post-injection at 60 CAD aTDC (Crank Angle Degrees after Top Dead Center). 
Table 5. Soot regeneration kinetic parameters.

\begin{tabular}{ccc}
\hline$P_{f}[\mathrm{~m} / \mathrm{s}]$ & $\mathrm{O}_{2}$ & 0.77 \\
\cline { 2 - 3 } $\mathrm{NO}_{2}$ & 6 \\
\hline$E_{a}[\mathrm{~J} / \mathrm{mol}]$ & $\mathrm{O}_{2}$ & $1 \times 10^{5}$ \\
\cline { 2 - 3 } & $\mathrm{NO}_{2}$ & $9.5 \times 10^{4}$ \\
\hline
\end{tabular}

The mass flow across the filter, the inlet gas temperature and the outlet pressure were imposed as a boundary condition to calibrate the model. Therefore, the objective was to predict the evolution of the pressure drop across the DPF and the outlet gas temperature. Being the mass flow constant, the temporal evolution of the pressure drop is a consequence of the soot loading and the gas temperature, which both depend on the soot oxidation rate. Figure 5a shows this comparison in terms of pressure drop, showing a very close match between experiments and simulations. Only a deviation is noticed at the very beginning of the test since the calibration gave more weight to the regeneration evolution than to the initial condition. Anyway, the model quickly converges to the experimental trace being capable to properly predict the pressure increase at the beginning of the regeneration due to the inlet gas temperature increase and the subsequent reduction as the soot mass load within the filter decreases. Similarly, Figure $5 \mathrm{~b}$ depicts the evolution of the temperature at the DPF outlet, well reproduced both during the thermal transient, finishing around second 300, as well as when the steady-state conditions are reached. In this case, a shift is again observed between the experimental and modelled DPF outlet temperature. As previously discussed, it is caused by the delay in the measured DPF inlet temperature. Despite that this measurement is more accurate than the one at the DOC inlet because of the DOC thermal inertia, it is still affected by the thermocouple characteristics. In turn, the DPF outlet temperature measurement is even more confident. Consequently, the shift in the outlet temperature provided by the models is more reduced at the DPF than in the DOC case, as also observed in Figure 6a concerning the DPF response during the WLTC test.

a)

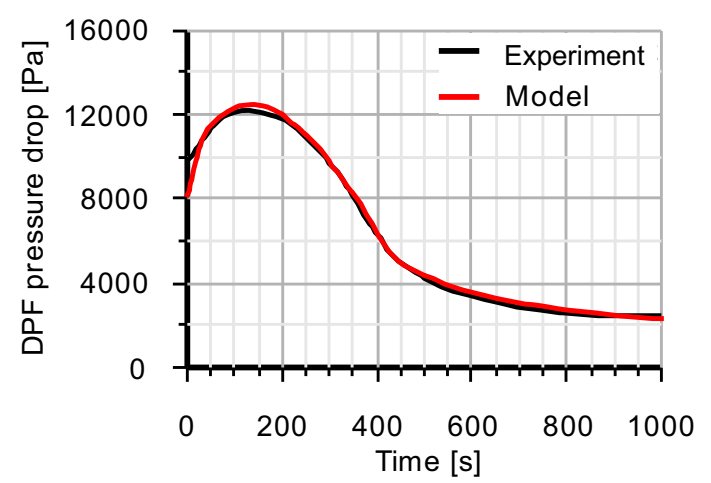

b)

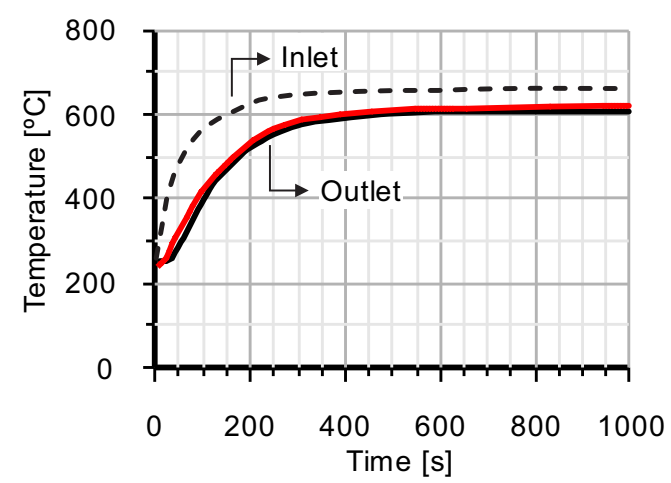

Figure 5. Comparison of experimental and modelled results during an active DPF regeneration event of (a) DPF pressure drop and (b) DPF gas temperature.

The passive soot oxidation during the WLTC test was also modelled to get further sensitivity in the calibration of the regeneration model. Taking the DOC outlet conditions related to Figure 4, Figure 6 shows the DPF outlet gas temperature and the cumulated soot mass during the cycle. In this case, the DPF model certifies the good prediction of the thermal response even with low soot oxidation rate. According to Figure $6 \mathrm{~b}$, the experimental filtrated soot mass is well captured by the model. In addition, the model provides the instantaneous soot mass load as a balance of filtrated and passively oxidised mass. Thus, the predicted soot mass at the end of the WLTC is $2.25 \mathrm{~g}$, which is very close to the experimental value obtained by DPF weighing [44]. 
a)

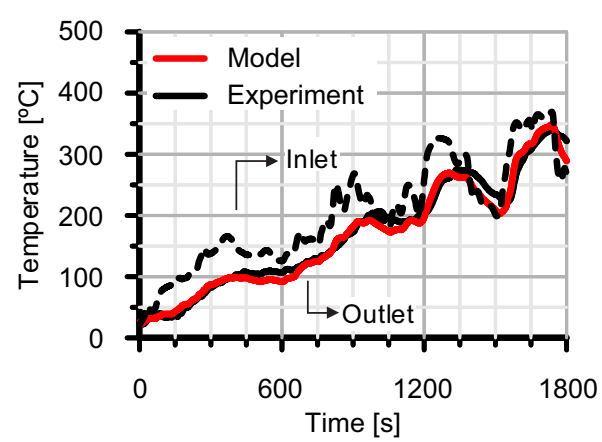

b)

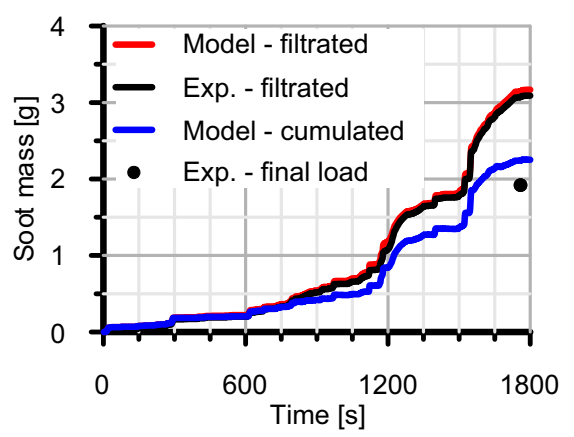

Figure 6. Comparison of experimental and modelled results during DPF passive regeneration under WLTC conditions of (a) DPF gas temperature and (b) DPF filtrated and cumulated soot.

\section{Engine and DOC Response}

Firstly, the effects of the late fuel post-injection on the engine performance and the gas properties in the exhaust are analysed varying the post-injected fuel mass rate and its timing. These results were achieved by using the gas dynamics engine model. Later on, the modelled flow properties at the turbine outlet, i.e., mass flow, pressure, temperature and composition, were imposed as boundary conditions to describe the response of the DOC.

Two engine operating points, which are defined in Table 6, are evaluated. A medium-high load operating point without EGR (\#A) is compared with a low load operating point with high HP-EGR rate (\#B). Both points share a similar raw $\mathrm{O}_{2}$ concentration but represent different boundaries for good pollutants abatement. To consider closed EGR in point \#A is an extreme case that is to evidence how the resulting DPF inlet temperature increases its sensitivity to the post-injection timing. It is representative of high in-cylinder temperature leading to the need to properly manage the late fuel post-injection timing. At the same time, low EGR rate engine operating conditions improve the dynamics of the soot oxidation in the DPF because of the high $\mathrm{O}_{2}$ concentration and mass availability after the DOC. It contrasts with the case of the same raw $\mathrm{O}_{2}$ concentration (DOC inlet, point \#B in Table 6) but high HP-EGR rate. This is representative of an operating condition which limits the available $\mathrm{O}_{2}$ mass across the DPF while at the same time providing high dwell time. The $\mathrm{O}_{2}$ availability makes the definition of the active regeneration strategy more dependent on the post-injected fuel mass rate.

Table 6. Operating points for DPF active regeneration analysis.

\begin{tabular}{lcc}
\hline Point ID & $\# \mathrm{~A}$ & $\# \mathrm{~B}$ \\
Engine speed [rpm] & 1250 & 1500 \\
Torque [Nm] & 168.7 & 74.5 \\
Engine load [\%] & 75 & 25 \\
EGR rate [\%] & 0 & 40.2 \\
Exhaust mass flow [kg/s] & 0.0307 & 0.0171 \\
Raw $\mathrm{O}_{2}$ concentration [\%] & 6.7 & 6.6 \\
DOC inlet temperature $\left[{ }^{\circ} \mathrm{C}\right]$ & 459 & 354 \\
DOC dwell time [ms] & 20.7 & 39.6 \\
DPF dwell time [ms] & 24.5 & 44.5 \\
\hline
\end{tabular}

Figure 7 shows the effect of the post-injection timing and the post-injected fuel mass rate on the brake specific fuel consumption (BSFC) and the torque. Figure 7 shows in plots (a) and (b) how the increase of the fuel mass in the post-injection leads to an increase of the BSFC for both operating points and over the complete range of the study. As described by Jeftić et al. [25] for high load and no-EGR conditions, point \#A shows higher sensitivity to the post-injection timing on BSFC. This happens because of the increase of the engine torque, which is especially relevant when the post-injection delay with respect to the main injection is small [27], as observed in Figure 7c and to a lesser extent in 
Figure $7 \mathrm{~d}$, in which the iso-torque lines evidence a lower slope. Thus, the torque increase becomes negligible as the post-injection is delayed, giving rise to a more evident penalty in BSFC, which gains dependence on the post-injected fuel mass rate for all points.
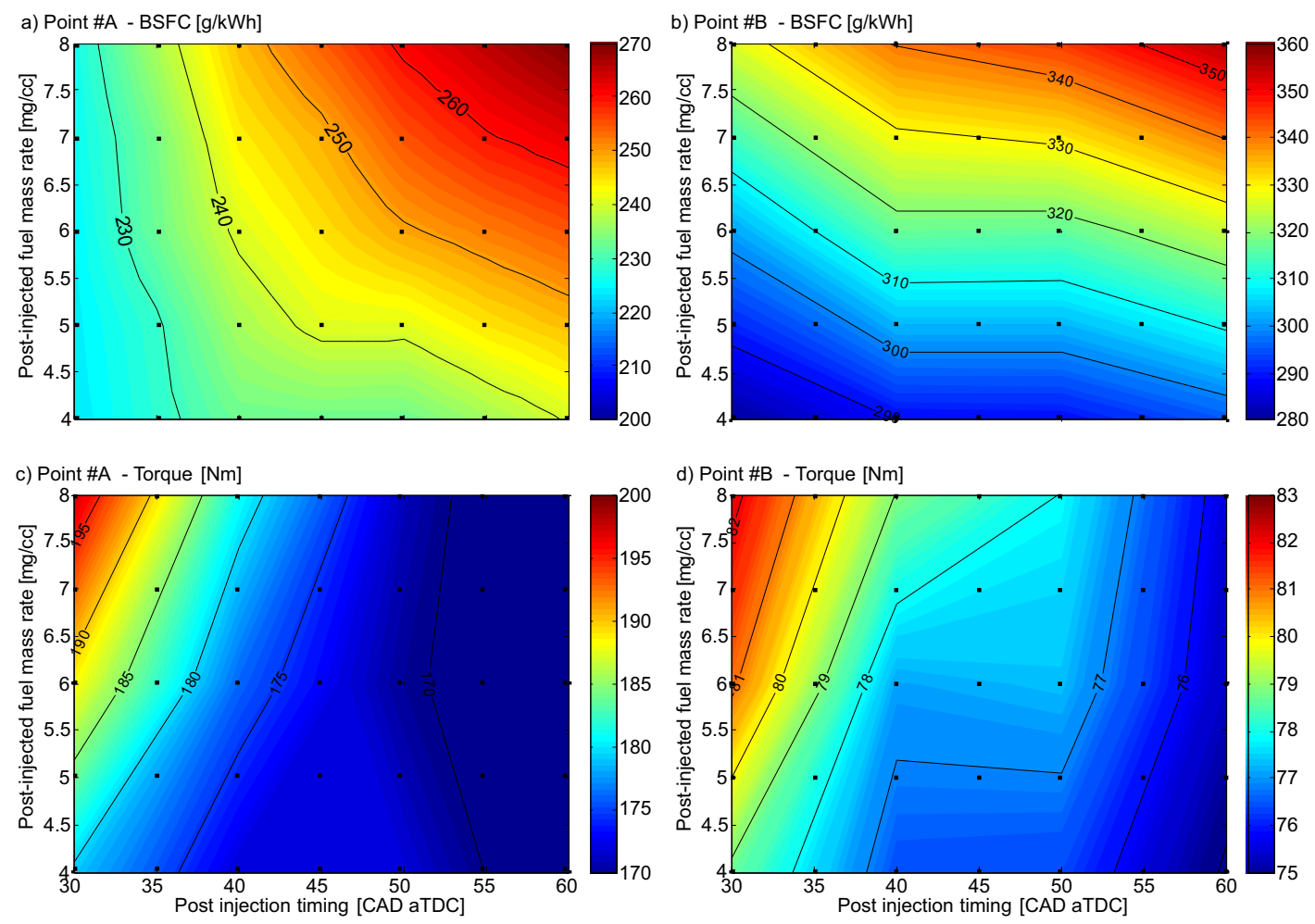

Figure 7. Effect of the post-injection timing and the post-injected fuel mass rate on the brake specific fuel consumption and the torque.

The impact of the late fuel post-injection on the raw $\mathrm{HC}$ and soot emissions is shown in Figure 8. Plot (a) in Figure 8 points out that point \#A is characterised by increasing raw HC concentration as the post-injection is delayed and as the post-injected fuel mass rate increases at high delays. This behaviour agrees with the high torque increase as the post-injected fuel mass rate is done at reduced delays and the loss of dependence with mass as the post-injection is further delayed. The lower sensitivity of torque in point \#B to the post-injected fuel mass rate, which is represented in Figure $8 \mathrm{~b}$, makes the raw $\mathrm{HC}$ concentration gain further dependence to this variable besides the post-injection timing. Regardless, the raw HC emission increases with the delay in the post-injection as the engine load decreases and EGR is used.

Concerning soot emission, Figure 8c shows that point \#A is greatly dependent on the post-injection delay, increasing as the post-injection is advanced due to the incomplete combustion of the fuel in these conditions [45]. Additionally, the increase of the temperature inside the cylinder induced by the partial combustion of post-injected fuel mass is not high enough to produce a relevant oxidation of the generated soot particles [46]. The trend in raw soot emissions completely changes in point $\# \mathrm{~B}$, as represented in Figure $8 \mathrm{~d}$. A lower increase of the soot emissions compared to point \#A is observed. This response is explained by the fact that the soot formation at low engine load is governed by the temperature of the gas inside the cylinder at the same time that the post-injection is performed. Being that this temperature is low, the reactions responsible of creating soot precursors are inhibited, thus avoiding the production of additional soot from the post-injection [45]. 

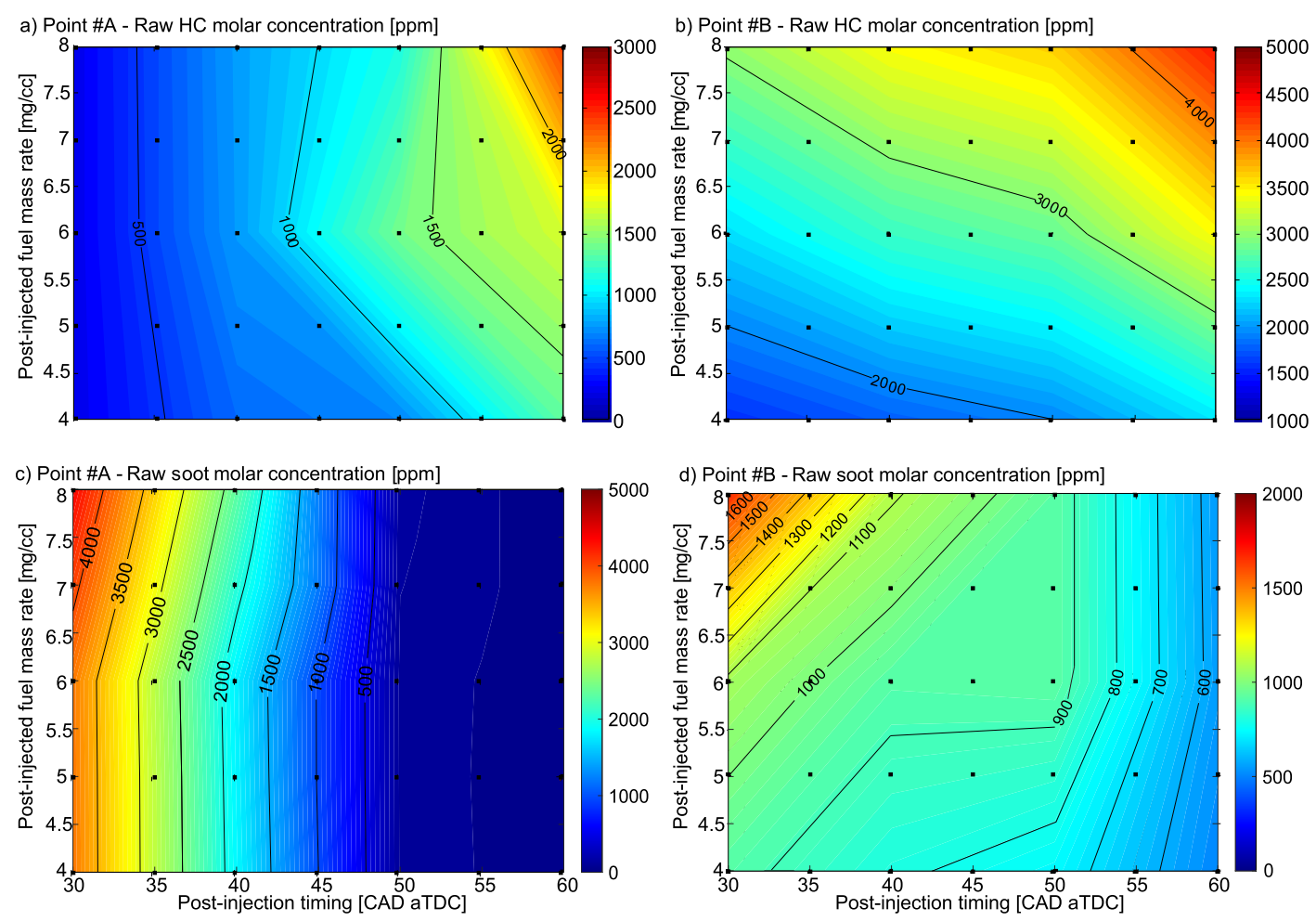

Figure 8. Effect of the post-injection timing and the post-injected fuel mass rate on the raw $\mathrm{HC}$ and soot emissions.

The boundary conditions at the DOC inlet are completed with the gas temperature, which is shown in Figure $9 \mathrm{a}$ and $\mathrm{b}$ for points \#A and \#B respectively. Comparing against Figure $7 \mathrm{c}, \mathrm{d}$, the DOC inlet temperature profile is observed to be almost identical to that in torque. Settings increasing the amount of post-injected fuel burned into the cylinder lead to an increase in torque and DOC inlet temperature. Therefore, the exhaust gas temperature increases as the post-injection is closer to the TDC and, to a lesser extent, the fuel mass increases, as also discussed experimentally by Yoon et al. [28].

By contrast, the pattern in the DOC outlet temperature is governed by the HC oxidation due to its high concentration, as plotted in Figure 9c,d. It is possible to observe how higher post-injected fuel mass rate produces the highest temperature increase across the DOC. The delay in the post-injection also favours the increase of the DOC outlet temperature. However, this effect is much more relevant in point \#A than in point \#B since it is intimately related to the amount of post-injected fuel mass burned into the cylinder. In fact, it can be noticed how in point \#A the region with the highest DOC outlet temperature corresponds to the lowest inlet one. The same conclusions are obtained from the analysis of point \#B. Nevertheless, the dependence of the DOC outlet temperature on the post-injection timing is lower due to the lower torque variation as a function of this parameter.

This response evidences that the increase in the DOC inlet temperature is caused by the oxidation of the post-injected fuel into the cylinders. This contributes to increase the torque and leads to a final lower temperature at the DOC outlet for the same post-injected fuel mass rate. In fact, Figure 9e,f indicate that the $\mathrm{O}_{2}$ concentration is only dependent on the post-injected fuel mass rate. In fact, it demonstrates that all the post-injected fuel is oxidised in the cylinder and/or the DOC. 

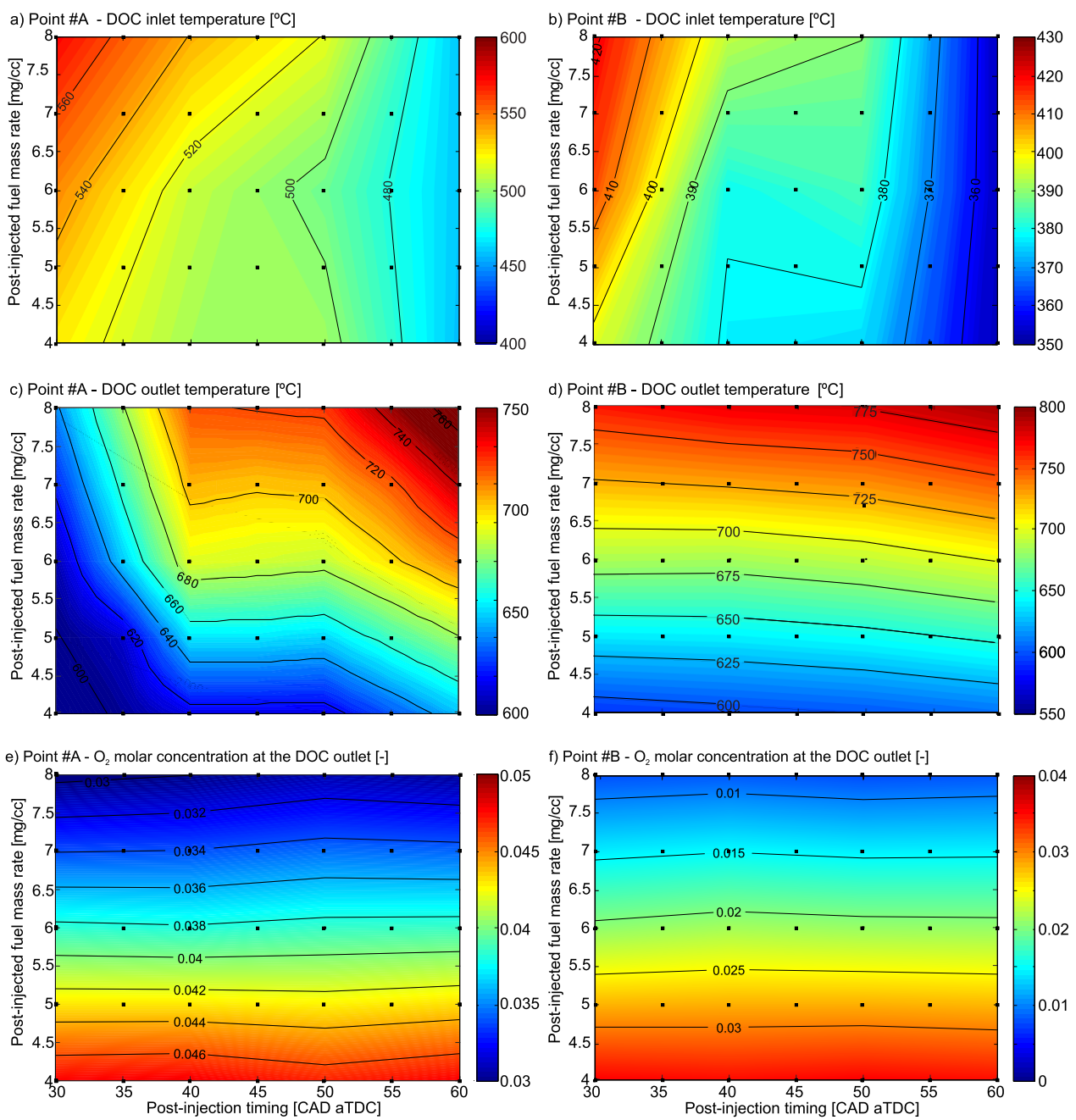

Figure 9. Effect of the post-injection timing and the post-injected fuel mass rate on the DOC gas temperature and the $\mathrm{O}_{2}$ concentration at the DOC outlet.

Taking into account the effects of the different post-injection settings on the temperature field, it is possible to quantify how efficiently the invested energy is converted into an increase of the temperature at the DOC outlet. Firstly, the maximum temperature at the DOC outlet can be calculated for each operating point as the one that should be reached if all the heat released by the oxidation of the post-injected fuel was used to increase the exhaust gas temperature at the DOC outlet:

$$
T_{D O C, \text { out }_{\max }}=T_{D O C, \text { out }_{\text {base }}}+\frac{\dot{m}_{f, P I} L H V}{\dot{m}_{\text {exh }} c_{p}} .
$$

The maximum temperature is represented by the continuous series in plots (a) and (b) of Figure 10 for each operating point and post-injected fuel mass rate. It is compared against the predicted temperature at the DOC outlet. The difference between theoretical and modelled values gets higher in both points as the post-injected fuel mass rate increases. Additionally, the predicted DOC outlet temperature is increasing as the post-injection is delayed. Therefore, the efficiency of the post-injection even increases as the post-injection is delayed. It is calculated according Equation (20) and represented in Figure 10c and d for points \#A and \#B respectively. In addition, these plots also make it evident that the lower the post-injected fuel mass rate is, the higher the post-injection efficiency is.

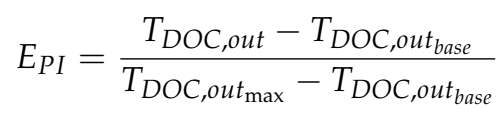


The trends in post-injection efficiency as a function of the timing and the fuel mass rate are mainly governed, as previously described, by the partial combustion of this fuel into the cylinders. If such an oxidation takes places, part of the energy available in the post-injection fuel mass contributes to useful work, thus increasing the torque; other second order effects on the post-injection efficiency are related to the VGT (variable-geometry turbocharger), which opens as the exhaust gas temperature increases and to the heat transfer until the DOC outlet. It is interesting to note that the lowest efficiency is obtained in point \#A, characterised by high load without EGR, when the post-injection delay is minimum. However, the efficiency sharply increases with a slight delay (from 30 to 40 CAD aTDC) and a monotonous increase is kept till 60 CAD aTDC. With this timing, both operating points show the same post-injection efficiency, i.e., the dependence of this parameter on the operating point disappears.
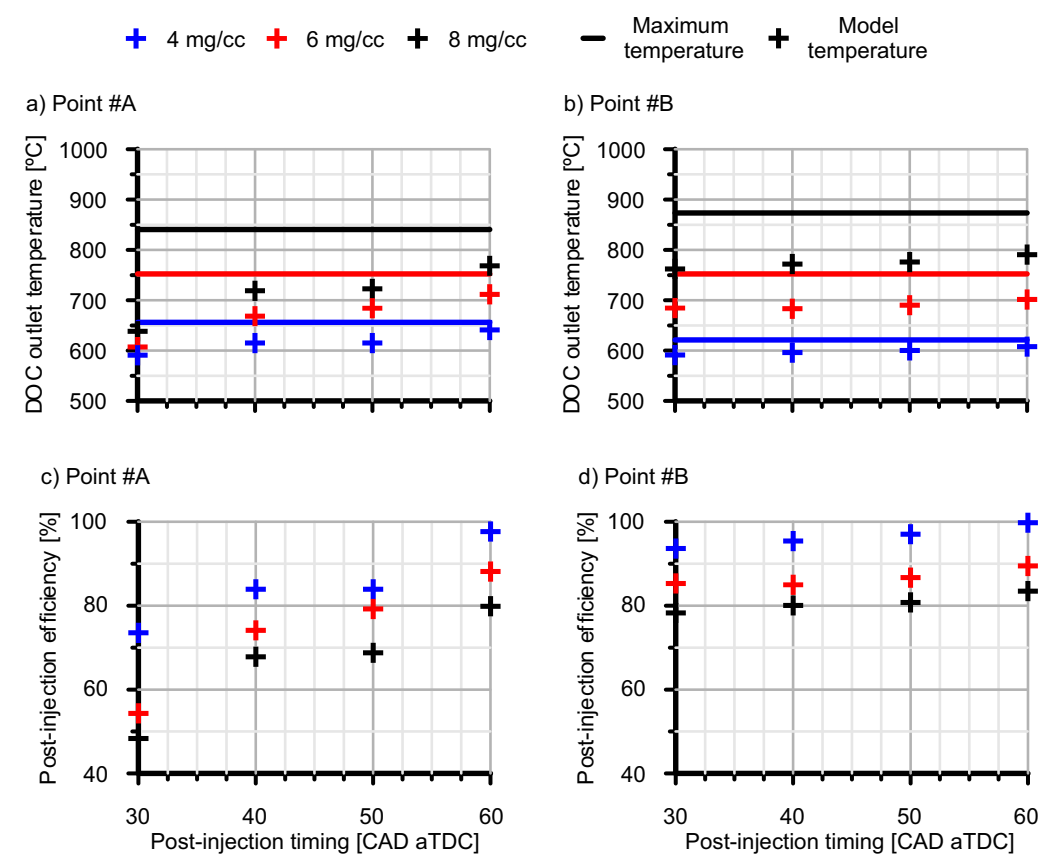

Figure 10. Post-injection efficiency as a function of the post-injection timing and the post-injected fuel mass rate.

\section{Active Regeneration Analysis}

Knowing the efficiency of the late fuel post-injection and the flow properties at the DPF inlet, the active regeneration process is next discussed. The gas composition, mass flow, pressure and temperature at the DOC outlet as a function of time, i.e., including the effect of the thermal transient due to the post-injected fuel heat release, were imposed as boundary conditions for the simulation of the DPF response. It was assumed that the initial DPF soot load of the filter was $11 \mathrm{~g} / \mathrm{L}$, which is a usual upper limit for the start of the regeneration [29].

The dynamics of the active regeneration is described based on the definition of the pre-heating, maximum reactivity and late oxidation stages [38]. Every stage is defined as a function of the derivative of the pressure drop across the DPF and the soot depletion rate. Figure 11a shows the evolution of the soot loading corresponding to the active regeneration used for the model calibration (Figure 5) in Section 2. The three regeneration stages are identified in Figure 11b. 
a)

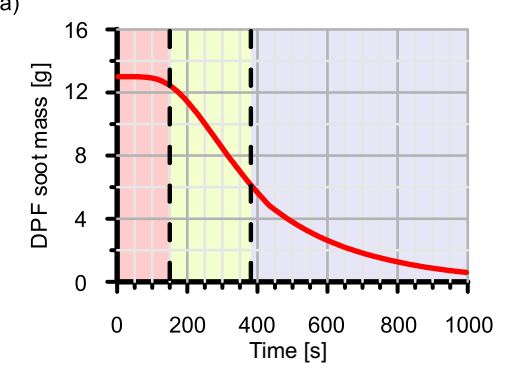

b)

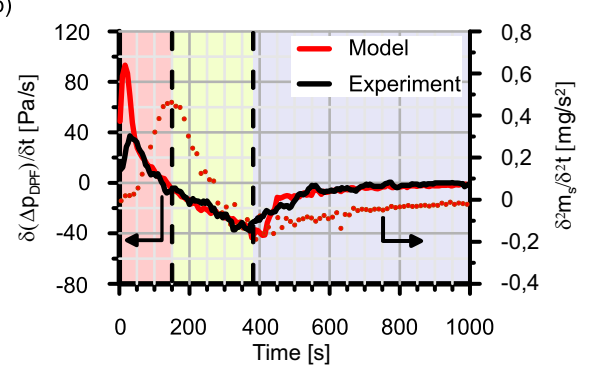

Figure 11. Dynamics of (a) the soot mass load and (b) the derivatives of the DPF pressure drop and the soot depletion rate along an active regeneration event.

The active regeneration event starts with an increase of the pressure drop across the DPF, i.e., positive pressure drop derivative, corresponding to the pre-heating stage. This increase is related to the increase in exhaust gas temperature. The deviation between the experimental and modelled pressure drop shown in Figure $5 \mathrm{a}$ at the beginning of the process causes the difference in pressure drop derivative observed in Figure 11b. Nevertheless, as the substrate increases its temperature the soot oxidation initiates, which causes a progressive decrease of the pressure drop rate as observed in the experimental and modelled results. Consequently, a sudden increase of the soot depletion rate derivative takes place. Once the pressure derivative becomes equal to zero, the maximum reactivity stage is started. This second stage lasts until the minimum in pressure drop derivative. Its duration coincides with the maximum to zero derivative in soot depletion rate. Finally, the regeneration is slowly completed during the late oxidation stage, which is characterised by a gradual smooth increase towards zero of the pressure drop and soot depletion rate derivatives.

Considering the parametric study for the late fuel post-injection parameters, Figure 12 depicts the duration of each active regeneration stage to achieve a consumption of $95 \%$ of the initial soot mass load. Both operating points confirm that a high delay in the post-injection is more convenient from the point of view of the velocity of the regeneration, independently of the post-injected fuel mass rate. Particularly, the best result is achieved when the post-injection is performed at 60 CAD aTDC for both engine operating points. These results are coincident with the trend shown in post-injection efficiency with respect to post-injection timing. This conclusion is also consistent with the work presented by Parks et al. [24], who established that the HC oxidation in the catalyst induces more efficient regeneration than the combustion inside the cylinders.

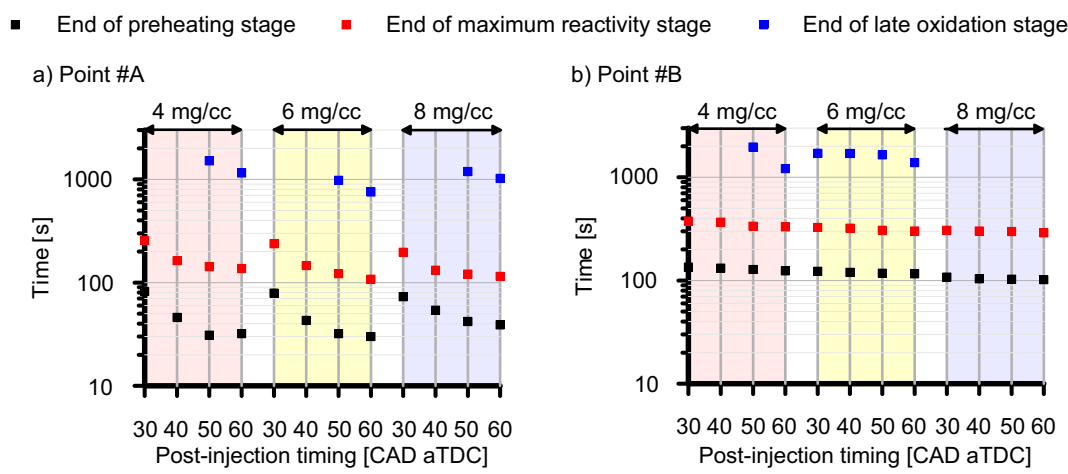

Figure 12. Effect of the variation of the post-injection timing and fuel mass on the duration of each regeneration stage.

It is also interesting to note that some post-injection strategies are not successful to complete the regeneration. Several phenomena are leading to this result. On the one hand, the lower efficiency in 
terms of DPF inlet temperature benefit of the earliest post-injections is combined with a significant increase of the soot emission, as shown in Figure 8. It leads the DPF to the equilibrium condition between soot filtration and oxidation rates.

On the other hand, Figure 10 shows that higher temperature is reached at the inlet of the DPF as the post-injected fuel mass rate increases. However, this condition is not enough to accelerate the regeneration. As observed in Figure 12, points \#A and \#B reach the fastest regeneration with 6 and $4 \mathrm{mg} / \mathrm{cc}$ respectively. The regeneration is not even able to be completed when post-injecting $8 \mathrm{mg} / \mathrm{cc}$ in the case of point \#B. The reason behind this limitation for post-injected fuel mass rate is the reduction in $\mathrm{O}_{2}$ concentration at the DPF inlet as the fuel mass increases, as observed in Figure 9 . Very low $\mathrm{O}_{2}$ concentration causes limitations to the chemical kinetics of the soot oxidation process [22]. These effects are more critical once the highest reactivity stage has finished, as observed in Figure 12.

With the aim of better understanding the boundaries defining the best post-injection settings, Figure 13 shows the DPF pressure drop, soot mass, outlet temperature and outlet $\mathrm{O}_{2}$ concentration during the fastest active regeneration for both operating points: $6 \mathrm{mg} / \mathrm{cc}$ and $60 \mathrm{CAD}$ aTDC in point \#A and $4 \mathrm{mg} / \mathrm{cc}$ and 60 CAD aTDC in point \#B. Plots (a) and (b) in Figure 13, which are related to the pressure drop and soot mass change along the regeneration, also include the duration of each of the regeneration stages for this fastest strategy. Additionally, two extreme regeneration strategies are plotted for each operating point: one with a post-injection timing of $30 \mathrm{CAD}$ aTDC but maintaining the post-injected fuel mass rate and another one with a fuel mass of $8 \mathrm{mg} / \mathrm{cc}$ but maintaining the timing at 60 CAD aTDC.
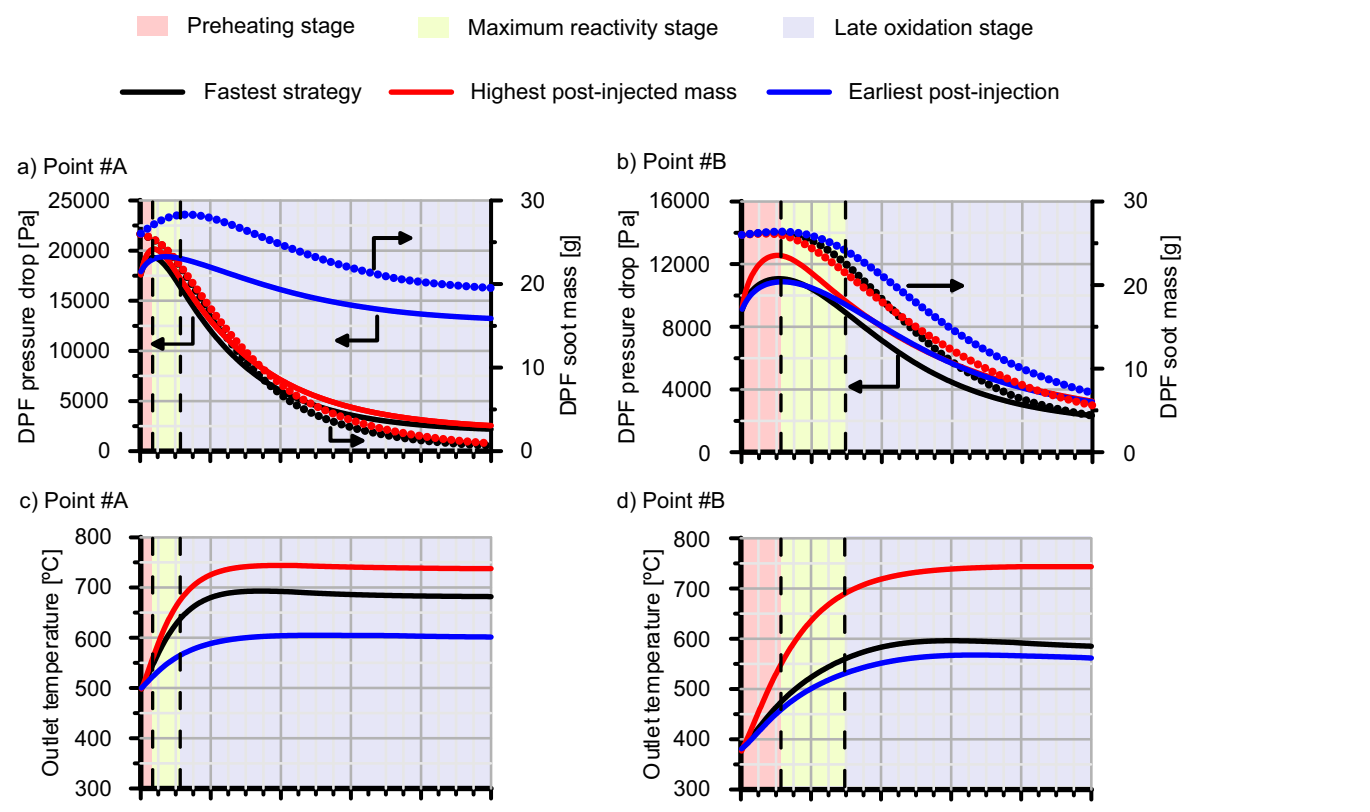

d) Point \#B
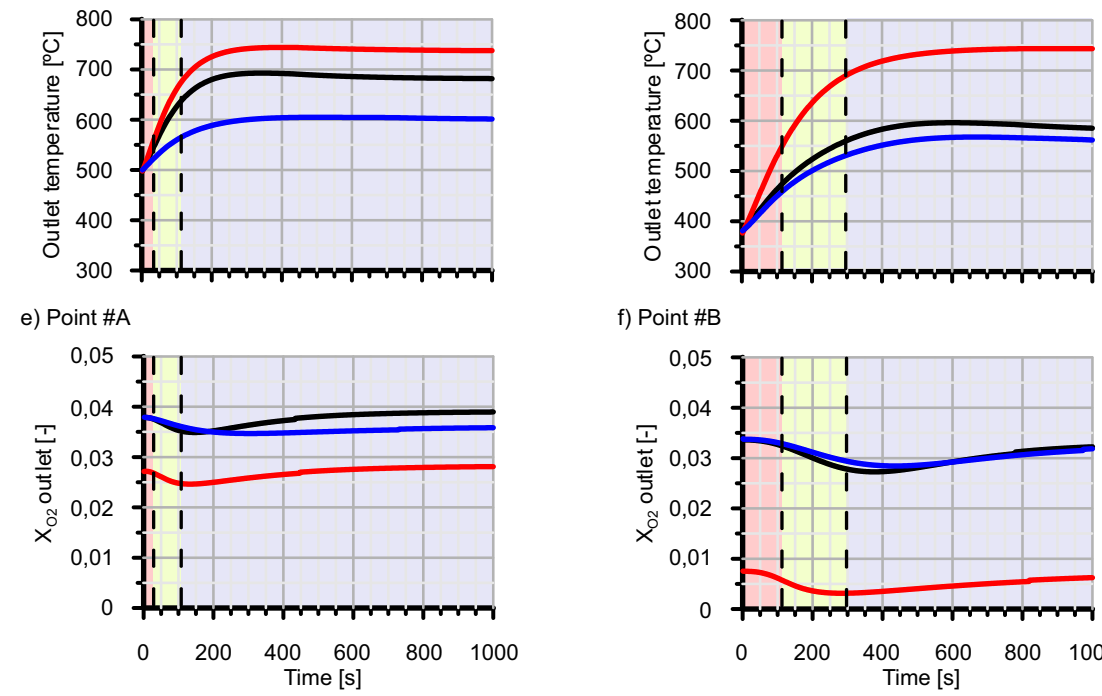

f) Point \#B

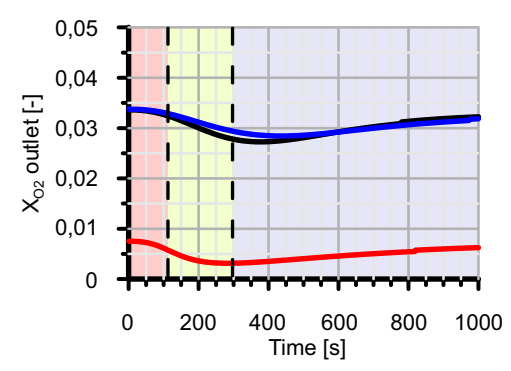

Figure 13. DPF pressure drop, soot mass, outlet temperature and outlet $\mathrm{O}_{2}$ concentration during the fastest active regeneration, advancing the post-injection and increasing the post-injected fuel mass rate. 
Point \#A is characterised by fast pre-heating and maximum reactivity stages due to its high DPF inlet temperature before triggering the active regeneration. Nevertheless, moving the post-injection settings to an early timing ( 30 CAD aTDC) gives as a result the minimum temperature at the DPF outlet $\left(600{ }^{\circ} \mathrm{C}\right)$, as observed in Figure 13c. It is still high enough to promote the soot oxidation. In fact, the $\mathrm{O}_{2}$ outlet concentration is very similar to that in the fastest strategy during the pre-heating and maximum reactivity stages (Figure 13e). However, the soot mass in the DPF decreases very slowly converging to the equilibrium condition (steady soot mass). As previously discussed, this is due to the increase in soot emission that is taking place for these post-injection settings (Figure 8c). The same behaviour is observed for point \#B when the post-injection is advanced. In this case, the lower DPF inlet temperature and, as a consequence, the longer thermal transient, produces longer pre-heating and maximum reactivity stages. In this case, the earliest post-injection case presents just slightly lower temperature than the fastest strategy and the $\mathrm{O}_{2}$ consumption is almost identical. This fact points out a very similar soot depletion rate. However, more soot mass is again found for the earliest post-injection case due to its higher raw soot emission rate (Figure $8 \mathrm{~d}$ ).

The representation of the highest post-injected fuel mass rate cases in Figure 13 makes evident the importance of the $\mathrm{O}_{2}$ availability on the oxidation rate. The highest DPF outlet temperature $\left(750{ }^{\circ} \mathrm{C}\right)$ is obtained when the post-injected fuel mass rate is increased to $8 \mathrm{mg} / \mathrm{cc}$ both in points \#A and \#B. However, the regeneration dynamics is not the fastest. In point \#A, the regeneration is almost as the fastest one $\left(6 \mathrm{mg} / \mathrm{cc}\right.$ ) but the decrease in $\mathrm{O}_{2}$ concentration (below $3 \%$ at the DPF outlet) makes the regeneration slower. In point $\# \mathrm{~B}$, the $\mathrm{O}_{2}$ concentration falls below $1 \%$ and slows the regeneration down significantly. In fact, coming back to Figure 12, the oxidised soot mass did not reach the $95 \%$ of the initial soot mass in $3000 \mathrm{~s}$.

As a final balance, Figure 14 shows the total post-injected fuel mass needed to complete the different regeneration stages. It results from the regeneration time and the post-injected fuel mass rate. As shown in Figure 14b, there is coincidence in point \#B between the post-injection settings providing the highest efficiency, the fastest regeneration and the minimum fuel consumption. This result was expected since the minimum post-injected fuel mass rate is also conducting to the fastest regeneration because of the high $\mathrm{O}_{2}$ concentration. However, point \#A shows interesting results in terms of fuel consumption. In this point the most efficient post-injection settings correspond to the lowest post-injected fuel mass rate $(4 \mathrm{mg} / \mathrm{cc})$. Despite that the regeneration is slower than the $6 \mathrm{mg} / \mathrm{cc}$ post-injected fuel mass rate case, the fuel consumption becomes clearly lower at the end of both the pre-heating and maximum reactivity stages. However, the late oxidation stage takes very long and the final fuel consumption during the regeneration loses the initial advantage and equals the $6 \mathrm{mg} / \mathrm{cc}$ case, which is fastest and, therefore, also the optimum. Nevertheless, taking the results of point \#B also into account, the optimum strategy seems to require low post-injected fuel mass rate but also ability to reach $600{ }^{\circ} \mathrm{C}$ in gas temperature during the pre-heating and maximum reactivity stages. Then, the baseline post-injected fuel mass rate should be increased during the late oxidation stage to increase further the gas temperature provided that no limitation in $\mathrm{O}_{2}$ availability was found.
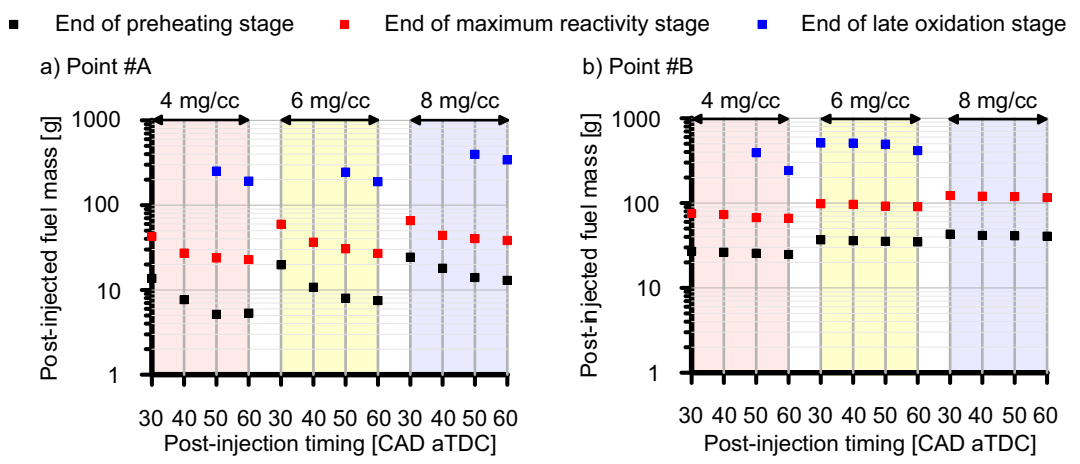

Figure 14. Post-injected fuel mass consumption to complete each regeneration stage. 


\section{Conclusions}

A study of the late fuel post-injection impact on the DPF active regeneration dynamics was presented. In particular, the engine fuel consumption, the flow properties at the DPF inlet and the regeneration duration were analysed with a modelling approach. The engine, DOC and DPF models were validated against experimental data corresponding to steady-state and transient operating conditions.

The most efficient way to increase the DPF inlet temperature was demonstrated to be the use of high delays in the post-injection since it reduces the amount of post-injected fuel burned out within the combustion chamber and, hence, generates useful work. This trend is particularly significant at high load and as the EGR rate gets reduced. In addition, delaying the post-injection avoids the increase of the soot emission that might lead the DPF to an incomplete regeneration when combined with small increase in DPF inlet temperature.

Increasing the post-injected fuel mass rate also contributes to obtaining higher DPF inlet temperature but at the expense of lower post-injection efficiency and the reduction of the $\mathrm{O}_{2}$ concentration. This can become a critical parameter slowing down the soot depletion rate dramatically and avoiding the regeneration completeness. In fact, the fastest regeneration events were shown to be those with low post-injected fuel mass rate, in particular around $20 \%$ of the fuel mass rate of the main injection. However, when the post-injected fuel consumption is also considered, the optimum post-injection strategy in terms of post-injected fuel mass rate is to set it to increase the DPF inlet temperature until $600{ }^{\circ} \mathrm{C}$ during the pre-heating and maximum reactivity stages. Although the soot depletion rate is not the maximum in these conditions, it is kept high due to high $\mathrm{O}_{2}$ concentration. The duration of the first two stages of the regeneration is not highly damaged and the fuel consumption is minimised in agreement with the maximum post-injection efficiency condition. Finally, to accelerate the late oxidation stage is positive. This stage is one order of magnitude longer than the previous ones due to the low soot depletion rate. To improve it, the post-injected fuel mass rate can be incremented if the $\mathrm{O}_{2}$ availability is a non-limiting factor. In these cases, higher gas temperature increases exponentially the depletion rate. As a consequence, the duration of the late oxidation stage is reduced and compensates the increase in the post-injected fuel mass rate.

Author Contributions: Conceptualization, J.R.S.; Formal analysis, P.P. and E.J.S.; Funding acquisition, J.R.S. and P.P.; Investigation, J.R.S., P.P., J.D.1.M. and E.J.S.; Methodology, J.D.1.M.; Project administration, J.R.S. and P.P.; Software, P.P. and E.J.S.; Supervision, P.P.; Writing—original draft, P.P., J.D.1.M. and E.J.S.; Writing一review \& editing, J.R.S., P.P., J.D.I.M. and E.J.S.

Funding: This work has been partially supported by FEDER and the Ministerio de Ciencia, Innovación y Universidades of the Government of Spain through Grant No. TRA2016-79185-R.

Conflicts of Interest: The authors declare no conflict of interest. The founding sponsors had no role in the design of the study; in the collection, analyses, or interpretation of data; in the writing of the manuscript, and in the decision to publish the results.

\section{Abbreviations}

The following abbreviations are used in this manuscript:

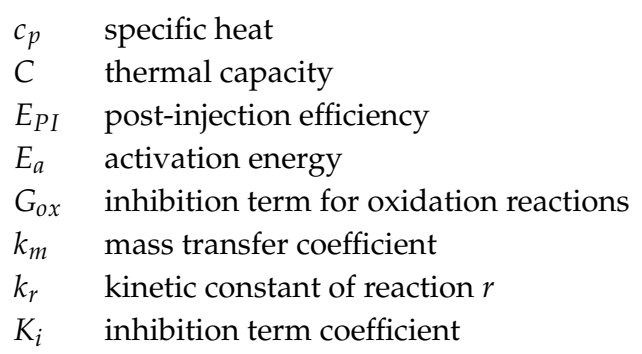




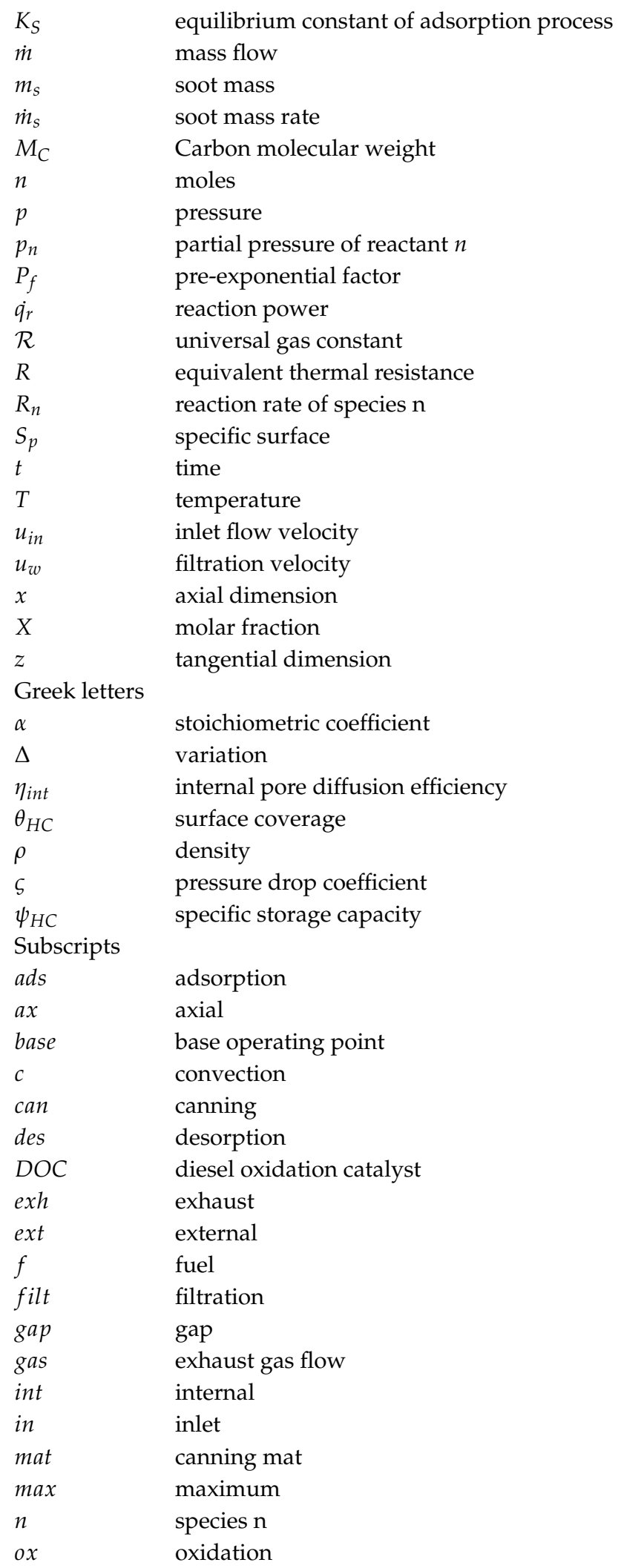




$\begin{array}{ll}\text { post } & \text { downstream } \\ \text { pre } & \text { upstream } \\ P I & \text { post-injection } \\ r & \text { radiation } \\ \text { rad } & \text { radial } \\ \text { reg } & \text { regeneration } \\ \text { shield } & \text { thermal shield } \\ \text { sur } & \text { canning surface } \\ \text { out } & \text { outlet } \\ w & \text { wall } \\ w c & \text { washcoat } \\ \text { Superscripts } & \\ p & \text { time step identifier } \\ \text { Abbreviations } & \\ \text { ATS } & \text { exhaust gas aftertreatment system } \\ \text { BSFC } & \text { brake specific fuel consumption } \\ \text { CAD aTDC } & \text { crank angle degrees after top dead center } \\ \text { DPF } & \text { diesel particulate filter } \\ \text { DOC } & \text { diesel oxidation catalyst } \\ \text { EGR } & \text { exhaust gas recirculation } \\ \text { GPF } & \text { gasoline particulate filter } \\ \text { HC } & \text { unburned hydrocarbons } \\ \text { HP-EGR } & \text { high pressure exhaust gas recirculation } \\ \text { HSDI } & \text { high speed direct injection } \\ \text { LHV } & \text { low fuel heating value } \\ \text { PF } & \text { wall-flow particulate filter } \\ \text { TDC } & \text { top dead center } \\ \text { VGT } & \text { variable geometry turbine } \\ \text { WLTC } & \text { Worldwide harmonized Light duty Test Cycle } \\ & \end{array}$

\section{References}

1. Joshi, A. Review of Vehicle Engine Efficiency and Emissions; SAE Technical Paper 2019-01-0314; SAE: Warrendale, PA, USA, 2019.

2. Seo, J.M.; Park, W.S.; Lee, M.J. The Best Choice of Gasoline/Diesel Particulate Filter to Meet Future Particulate Matter Regulation; SAE Technical Paper 2012-01-1255; SAE: Warrendale, PA, USA, 2019.

3. Chan, T.W.; Meloche, E.; Kubsh, J.; Rosenblatt, D.; Brezny, R.; Rideout, G. Evaluation of a gasoline particulate filter to reduce particle emissions from a gasoline direct injection vehicle. SAE Int. J. Fuels Lubr. 2009, 5, 1277-1290. [CrossRef]

4. Cooper, J.D.; Liu, L.; Ramskill, N.P.; Watling, T.C.; York, A.P.E.; Stitt, E.H.; Sederman, A.J.; Gladden, L.F. Numerical and experimental studies of gas flow in a particulate filter. Chem. Eng. Sci. 2019, 209, 115179. [CrossRef]

5. Guo, Y.; Stevanovic, S.; Verma, P.; Jafari, M.; Jabbour, N.; Brown, R.; Cravigan, L.; Alroe, J.; Osuagwu, C.G.; Brown, R.; et al. An experimental study of the role of biodiesel on the performance of diesel particulate filters. Fuel 2019, 247, 67-76. [CrossRef]

6. Zhao, C.; Zhu, Y.; Huang, S. Pressure Drop and Soot Accumulation Characteristics through Diesel Particulate Filters Considering Various Soot and Ash Distribution Types; SAE Technical Paper 2017-01-0959; SAE: Warrendale, PA, USA, 2017.

7. Torregrosa, A.J.; Piqueras, P.; Sanchis, E.J.; Guilain, S.; Dubarry, M. Assessment of acoustic reciprocity and conservativeness in exhaust aftertreatment systems. J. Sound Vib. 2018, 436, 46-61. [CrossRef]

8. Bermúdez, V.; Serrano, J.R.; Piqueras, P.; Sanchis, E.J. On the impact of particulate matter distribution on pressure drop of wall-flow particulate filters. Appl. Sci. 2017, 7, 234. [CrossRef]

9. Rodríguez-Fernández, J.; Lapuerta, M.; Sánchez-Valdepeñas, J. Regeneration of diesel particulate filters: Effect of renewable fuels. Renew. Energy 2017, 104, 30-39. [CrossRef] 
10. Lambert, C.; Chanko, T.; Dobson, D.; Liu, X.; Pakko, J. Gasoline particle filter development. Emiss. Contr. Sci. Technol. 2017, 3, 105-111. [CrossRef]

11. Bensaid, S.; Marchisio, D.L.; Fino, D. Numerical simulation of soot filtration and combustion within diesel particulate filters. Chem. Eng. Sci. 2010, 35, 357-363. [CrossRef]

12. Guan, B.; Zhan, R.; Lin, H.; Huang, Z. Review of the state-of-the-art of exhaust particulate filter technology in internal combustion engines. J. Environ. Manag. 2015, 154, 225-258. [CrossRef]

13. Kotrba, A.; Gardner, T.P.; Bai, L.; Yetkin, A. Passive Regeneration Response Characteristics of a DPF System; SAE Technical Paper 2013-04-08; SAE: Warrendale, PA, USA, 2013.

14. Joshi, A.; Johnson, T.V. Gasoline Particulate Filters-A Review. Emission Contr. Sci. Technol. 2018, 4, $219-239$. [CrossRef]

15. Jiaqiang, E.; Zhao, X.; XIe, L.; Zhang, B.; Chen, J.; Zuo, Q.; Han, D.; Hu, W.; Zhiqing, Z. Performance enhancement of microwave assisted regeneration in a wall-flow diesel particulate filter based on field synergy theory. Energy 2019, 169, 719-729. [CrossRef]

16. O'Connor, J.; Musculus, M. Post injections for soot reduction in Diesel engines: A review of current understanding. SAE Int. J. Engines 2013, 6, 400-421. [CrossRef]

17. Beatrice, C.; Di Iorio, S.; Guido, C.; Napolitano, P. Detailed characterization of particulate emissions of an automotive catalyzed DPF using actual regeneration strategies. Exp. Therm. Fluid Sci. 2012, 39, 45-53. [CrossRef]

18. Guardiola, C.; Pla, B.; Piqueras, P.; Mora, J.; Lefebvre, D. Model-based passive and active diagnostics strategies for diesel oxidation catalysts. Appl. Therm. Eng. 2017, 110, 962-971. [CrossRef]

19. Singh, N.; Rutland, C.J.; Foster, D.E.; Narayanaswamy, K.; He, Y. Investigation into Different DPF Regeneration Strategies Based on Fuel Economy Using Integrated System Simulation; SAE Technical Paper 2009-01-1275; SAE: Warrendale, PA, USA, 2009.

20. Ko, J.; Si, W.; Jin, D.; Myung, C.; Park, S. Effect of active regeneration on time-resolved characteristics of gaseous emissions and size-resolved particle emissions from light-duty diesel engine. J. Aerosol Sci. 2016, 91, 62-77. [CrossRef]

21. Bouchez, M.; Dementhon, J.B. Strategies for the Control of Particulate Trap Regeneration; SAE Technical Paper 2000-01-0472; SAE: Warrendale, PA, USA, 2000.

22. Lapuerta, M.; Hernández, J.J.; Oliva, F. Strategies for active diesel particulate filter regeneration based on late injection and exhaust recirculation with different fuels. Int. J. Engine Res. 2014, 15, 209-221. [CrossRef]

23. Mayer, A.; Lutz, T.; Lämmle, C.; Wyser, M.; Legerer, F. Engine Intake Throttling for Active Regeneration of Diesel Particle Filters; SAE Technical Paper 2003-01-0381; SAE: Warrendale, PA, USA, 2003.

24. Parks, J.; Huff, S.; Kass, M.; Storey, J. Characterization of in-Cylinder Techniques for Thermal Management of Diesel Aftertreatment; SAE Technical Paper 2007-01-3997; SAE: Warrendale, PA, USA, 2007.

25. Jeftić, M.; Tjong, J.; Reader, G.; Wang, M.; Zheng, M. Combustion and Exhaust Gas Speciation Analysis of Diesel and Butanol Post Injection; SAE Technical Paper 2015-01-0803; SAE: Warrendale, PA, USA, 2015.

26. Piqueras, P.; García, A.; Monsalve-Serrano, J.; Ruiz, M.J. Performance of a diesel oxidation catalyst under diesel-gasoline reactivity controlled compression ignition combustion conditions. Energy Convers. Manag. 2019, 196, 18-31. [CrossRef]

27. Chen, P.; Ibrahim, U.; Wang, J. Experimental investigation of diesel and biodiesel post injections during active diesel particulate filter regenerations. Fuel 2014, 130, 286-295. [CrossRef]

28. Yoon, S.; Kim, H.; Kim, D.; Park, S. Effect of fuel injection strategy on DPF regeneration in single cylinder diesel engine. In Proceedings of the ASME 2015 Internal Combustion Engine Division Fall Technical Conference (ICEF2015), Houston, TX, USA, 8-11 November 2015.

29. Boger, T.; Rose, D.; Tilgner, I.C.; Heibel, A.K. Regeneration strategies for an enhanced thermal management of oxide diesel particulate filters. SAE Int. J. Fuels Lubr. 2009, 1, 162-172. [CrossRef]

30. GT-Power User's Manual. In GT-Suite ${ }^{T M}$, version 7.4; Gamma Technologies: Westmont, IL, USA, 2013.

31. Luján, J.M.; Serrano, J.R.; Piqueras, P.; Diesel, B. Turbine and exhaust ports thermal insulation impact on the engine efficiency and aftertreatment inlet temperature. Appl. Energy 2019, 240, 409-423. [CrossRef]

32. OpenWAM Website, CMT-Motores Tèrmicos (Universitat Politècnica de València). 2019. Available online: www.openwam.org (accessed on 5 November 2019). 
33. Galindo, J.; Serrano, J.R.; Arnau, F.J.; Piqueras P. Description of a semi-independent time discretization methodology for a one-dimensional gas dynamics model. J. Eng. Gas Turb. Power 2009, 131, 034504. [CrossRef]

34. Serrano, J.R.; Olmeda, P.; Arnau, F.J.; Dombrovsky, A.; Smith, L. Analysis and methodology to characterize heat transfer phenomena in automotive turbochargers. J. Eng. Gas Turb. Power 2015, 137, 021901. [CrossRef]

35. Serrano, J.R.; Olmeda, P.; Arnau, F.J.; Dombrovsky, A. Turbocharger heat transfer and mechanical losses influence in predicting engines performance by using one-dimensional simulation codes. Energy 2015, 86, 204-218. [CrossRef]

36. Payri, F.; Arnau, F.J.; Piqueras, P.; Ruiz, M.J. Lumped Approach for Flow-Through and Wall-Flow Monolithic Reactors Modelling for Real-Time Automotive Applications; SAE Technical Paper 2018-01-0954; SAE: Warrendale, PA, USA, 2018.

37. Galindo, J.; Serrano, J.R.; Piqueras, P.; García-Afonso, Ó. Heat transfer modelling in honeycomb wall-flow diesel particulate filters. Energy 2012, 43, 201-213. [CrossRef]

38. Macián, V.; Serrano, J.R.; Piqueras, P.; Sanchis, E.J. Internal pore diffusion and adsorption impact on the soot oxidation in wall-flow particulate filters. Energy 2019, 179, 407-421. [CrossRef]

39. Gieshoff, J.; Schär-Sindlinger, A.; Spurk, P.C.; van den Tillaart, J.A.A.; Garr, G. Improve SCR Systems for Heavy Duty Applications; SAE Technical Paper 2000-01-0189; SAE: Warrendale, PA, USA, 2000.

40. Serrano, J.R.; Climent, H.; Piqueras, P.; Angiolini, E. Filtration modelling in wall-flow particulate filters of low soot penetration thickness. Energy 2016, 112, 883-898. [CrossRef]

41. Serrano, J.R.; Arnau, F.J.; Piqueras, P.; García-Afonso, Ó; Packed bed of spherical particles approach for pressure drop prediction in wall-flow DPFs (diesel particulate filters) under soot loading conditions. Energy 2013, 58, 644-654. [CrossRef]

42. Oh, S.H.; Cavendish, J.C. Transients of monolithic catalytic converters. Response to step changes in feedstream temperature as related to controlling automobile emissions. Ind. Eng. Chem. Prod. Res. Dev. 1982, 21, 29-37. [CrossRef]

43. Guardiola, C.; Dolz, V.; Pla, B.; Mora, J. Fast estimation of diesel oxidation catalysts inlet gas temperature. Control Eng. Pract. 2016, 56, 148-156. [CrossRef]

44. Luján, J.M.; Serrano, J.R.; Piqueras, P.; García-Afonso, Ó. Experimental assessment of a pre-turbo aftertreatment configuration in a single stage turbocharged diesel engine. Part 2: Transient operation. Energy 2015, 80, 614-627. [CrossRef]

45. Desantes, J.M.; Arrègle, J.; López, J.J.; García, A. A Comprehensive Study of Diesel Combustion and Emissions with Post-Injection; SAE Technical Paper 2007-01-0915; SAE: Warrendale, PA, USA, 2007.

46. Hessel, R.; Reitz, R.; Musculus, M.; O'Connor, J.; Flowers, D. A CFD study of post injection influences on soot formation and oxidation under diesel-like operating conditions. SAE Int. J. Engines 2014, 7, 694-713. [CrossRef]

(C) 2019 by the authors. Licensee MDPI, Basel, Switzerland. This article is an open access article distributed under the terms and conditions of the Creative Commons Attribution (CC BY) license (http://creativecommons.org/licenses/by/4.0/). 